Canadian

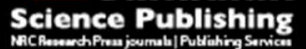

Canadian Journal of Civil Engineering Revue canadienne de génie civil

\title{
Strength behavior of plain cement concrete subjected to true-triaxial Compression
}

\begin{tabular}{|c|c|}
\hline Journal: & Canadian Journal of Civil Engineering \\
\hline Manuscript ID & cjce-2017-0114.R2 \\
\hline Manuscript Type: & Article \\
\hline Date Submitted by the Author: & 20-Oct-2017 \\
\hline Complete List of Authors: & $\begin{array}{l}\text { RUKHAIYAR, SAURAV; Indian Institute of Technology Roorkee, CIVIL } \\
\text { ENGINEERING } \\
\text { Sajwan, Gaurav; Indian Institute of Technology Roorkee, CIVIL } \\
\text { ENGINEERING } \\
\text { Samadhiya, Narendra; Indian Institute of Technology Roorkee, CIVIL } \\
\text { ENGINEERING }\end{array}$ \\
\hline $\begin{array}{r}\text { Is the invited manuscript for } \\
\text { consideration in a Special } \\
\text { Issue? : }\end{array}$ & N/A \\
\hline Keyword: & $\begin{array}{l}\text { True-triaxial compression test, Plain cement concrete, Intermediate } \\
\text { principal stress, Hsieh-Ting-Chen criterion, Drucker-Prager }\end{array}$ \\
\hline
\end{tabular}


1 Title: Strength behavior of plain cement concrete subjected to true-triaxial

2 Compression.

3 Authors

4 1. Saurav Rukhaiyar (Corresponding Author)

5 Research Scholar

6 Department of Civil Engineering,

7 Indian Institute of Technology Roorkee, Roorkee 247667, Uttarakhand, India.

$8 \quad$ email: saurav.rukhaiyar@gmail.com

$9 \quad$ Tel: $+91-7520093692$

10

11 2. Gaurav Sajwan

12 Postgraduate student

Department of Civil Engineering,

Indian Institute of Technology Roorkee, Roorkee 247667, Uttarakhand, India.

email: gauravsajwan14@gmail.com

17 3. Narendra Kumar Samadhiya, Ph.D.

18 Professor

Department of Civil Engineering, Indian Institute of Technology Roorkee, Roorkee 247667, Uttarakhand, India. e-mail: nksamfce@iitr.ernet.in

Tel: +91-9412073058 
45

\section{Abstract}

True-triaxial compression test was conducted on $100 \mathrm{~mm}$ x $100 \mathrm{~mm}$ x $100 \mathrm{~mm}$ cubical sample of plain cement concrete using the true-triaxial testing machine. A total of 30 tests were conducted on two mix of concrete having characteristic strengths of $24.39 \mathrm{MPa}$ and 34.67 MPa. The minor and intermediate principal stresses were varied from 2.5 MPa to 10 $\mathrm{MPa}$ and 2.5 $\mathrm{MPa}$ to $30 \mathrm{MPa}$ respectively. The samples were loaded till failure under the stress rate of $1 \mathrm{MPa} / \mathrm{min}$. The failure mode and direction of fracture planes were observed carefully. It was observed that the ratio of intermediate and minor principal stress had an incremental effect on the strength of the concrete. The results obtained from our experimental study as well as the true-triaxial compression test data published in literature has been used to conduct a quantitative evaluation of three commonly used failure criteria presented for the concrete. The three failure criteria considered are Drucker-Prager (DP) criterion, BreslerPester (BP) criterion and Hsieh-Ting-Chen (HTC) criterion. It was observed that for the normal strength concrete, the HTC criterion predicts the strength with least error while for the high strength concrete, the DP criterion have a better prediction. Overall the DP and BP criterion underestimates the strength while the HTC criterion overestimates.

Keyword: True-triaxial compression test, Plain cement concrete, Intermediate principal stress, Hsieh-Ting-Chen criterion, Drucker-Prager criterion 


\subsection{Introduction}

The constitutive behavior and relationship of the plain cement concrete (PCC) must be understood before modeling the structural response of any concrete structure. The behavior of concrete varies with the state of confinement and hence the constitutive relation also changes. Concrete structure such as the shear wall, spiral columns, nodes of the building, pressure container of the nuclear reactors are some of the cases, where concrete in general remains in state of confinements (He and Song 2010). The confinement states in mentioned structures are generally uniaxial $\left(\sigma_{1}>\sigma_{2}=\sigma_{3}=0\right)$, biaxial $\left(\sigma_{1} \geq \sigma_{2}>\sigma_{3}=0\right)$ and multiaxial state of stress which include both triaxial compression $\left(\sigma_{1}>\sigma_{2}=\sigma_{3}>0\right)$ and true-triaxial compression $\left(\sigma_{1}>\right.$ $\left.\sigma_{2}>\sigma_{3}>0\right)$ conditions. The indices $\sigma_{1}, \sigma_{2}$, and $\sigma_{3}$ represent the major, intermediate and minor principal stresses respectively. The mechanical response of the concrete depends upon the state of stress and hence intermediate principal stress influences the constitutive response. Experimental testing of concrete under the various condition of confinement helps in establishing fundamental characteristic of concrete. Analytical models are developed to describe these fundamental characteristics which were further refined and calibrated using experimental data.

The behavior of concrete under the multiaxial state of stresses has been experimentally studied for last 7 decades. The pioneering work are those of Balmar (1949), Akroyd (1961), Chin and Zimmerman (1965), Kupfer et al. (1969), Mills and Zimmerman (1970), Lounay and Gachon (1972), Kotsovos and Newman (1978), Wastiels (1979), Gerstle et al. (1980),

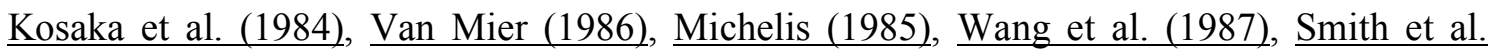
(1989), Imran and Pantazopoulou (1996), Li and Ansari (1999), Sfer et al. (2002), Ahmad and Ajarloo (2005), Petkovski et al. (2006), Hampel et al. (2009), Gabet et al. (2008), Vu et al. (2009 a and b), Liu and Song (2010), Malecot et al. (2010), Vu et al. (2011), Petkovski (2013), Shang and Li (2014), Zhou et al. (2014) and Vu et al. (2015). However, most of the 
researchers have conducted testing under the triaxial conditions only on cylindrical or cubical samples. Most of these studies are also conducted at very moderate confining pressure. Gabet

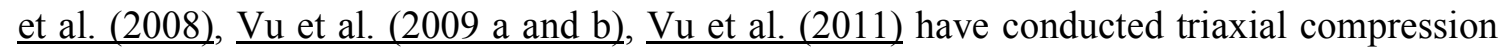
test on concrete using GIGA press facility in Grenoble which has cell pressure capacity of upto $1 \mathrm{GPa}$. Testing under true-triaxial conditions is very rare. Very few researchers attempted true-triaxial testing using their self-designed machines which can apply all the three principal stresses independently. True-triaxial test on concrete was attempted by some researchers (Mills and Zimmerman 1970; Van Mier 1986; Wang et al. 1987; Hampel et al. 2009; He and Song 2010; Liu and Song 2010; Shang and Li 2014; Zhou et al. 2014). Petkovski et al. (2006) in university of Sheffield have developed an apparatus for testing concrete under true-triaxial compression at elevated temperature. He along with his colleagues studied the effect of different heat-load regimes on the strains under transient hygro-thermal states, stress-strain behaviour and damage evolution in concrete subjected to true-triaxial compression (Petkovski and Crouch 2008; Petkovski 2010 and Petkovski 2013). $\underline{\text { He and Song (2010) }}$ also studied the behaviour of high strength and high-performance concrete under true-triaxial compression before and after exposure to high temperatures.

Several failure criteria have been presented by various researchers to model the behavior of concrete under the multiaxial state of stress. Most of these criteria had been developed with the basics of the failure theories developed for the metals. These theories have been modified for the concrete using biaxial and multiaxial experimental data as well as considering the various shape of failure surface in the deviatoric plane. These failure criteria have been categorized based on the number of parameters included in the same. Table 1 presents a list of commonly used concrete failure criteria under the multiaxial state of stress.

Based on the literature review, it has been felt that the laboratory studies on the truetriaxial behavior of concrete are very few. To have better and more realistic constitutive 
relationships, more studies are the need of the hour. A quantitative evaluation of strength criteria is also needed. The present article discusses in detail, an experimental study wherein concrete of two different characteristic strengths have been tested under the true-triaxial state of compression. The strength behavior of plain cement concrete has been studied. The result of present experimental study along with the results published in literature has been used to statistically evaluate the three classical multiaxial strength criteria developed for the concrete.

\subsection{Experimental program}

\subsection{Materials}

Ordinary Portland cement (OPC) conforming to IS: 8112-1989 (2005) was used as the binder. Table 2 presents the physical properties of OPC. Locally available river sand having fineness modulus in the range of 2.6 to 2.9 conforming to IS: 383-1970 (2002) was used as the fine aggregate. Aggregate in its natural form (uncrushed river gravel) having the maximum size of $12.5 \mathrm{~mm}$ was used as the coarse aggregate. Table 3 presents the physical properties of the coarse and fine aggregates. The Impact value and aggregate crushing value as presented in Table 3 were obtained as per procedure given in IS: 2386 (part IV)-1963 (1999). Potable water was used for mixing of constituents. Two types of concrete having 28day target strength of $20 \mathrm{MPa}$ and $30 \mathrm{MPa}$ respectively were designed. These mixes are identified as M20 and M30 concrete respectively. The concretes were designed using the absolute volume method as per IS 10262-2009 (2009). The mix proportions of the M20 and M30 Concrete have been presented in Table 4. The constituent materials were mixed thoroughly. The concrete cubes were cast in steel molds which were vibrated well to ensure uniformity. The samples were cured for 28 days. 
Cubical samples having the nominal dimension of $100 \mathrm{~mm} \times 100 \mathrm{~mm} \times 100 \mathrm{~mm}$ were prepared and used for the true-triaxial tests and the uniaxial tests. The samples were carefully grounded and lapped on the entire surface and their orthogonality was checked.

\subsection{Testing apparatus}

The testing was conducted in the true-triaxial testing machine developed by the WilleGeotechnik, Germany. The machine consists of four different units as shown in Fig. 1. The units are the sample holder, the power-pack, pressure intensifiers and the workstation. The sample holder has three pairs of piston system attached with it from $\mathrm{X}, \mathrm{Y}$ and $\mathrm{Z}$ directions. The stress on the concrete is applied with the help of pressure or loading platen having the dimension of $94 \mathrm{~mm} \times 94 \mathrm{~mm}$. The loading platens are attached with the sample holder's piston system. Fig. 2 shows the closer view of sample holder, the pressure platen and the piston system. The power-pack generates the initial pressure which gets intensified in the intensifiers. The intensifier maintains the pressure in the sample holder's piston system. The maximum stress that can be applied by the machine on the concrete samples from any direction is $140 \mathrm{MPa}$. The LVDT associated with the loading platen measures the displacement in all the six directions. The displacement measured has been used to calculate the strain in the samples. The complete system is fully automated and controlled by the GEOsys software. The testing is controlled and coordinated with the help of the workstation.

\subsection{Test program}

The tests have been conducted for compression only. Five uniaxial compression strength tests have been conducted on the cubical samples of the same size for each concrete mix. The average value of uniaxial compressive strength has been designated as characteristics strength $\left(f_{c}\right)$ of concrete mix.

A total of thirty true-triaxial tests have been conducted on cubical sample plain cement concrete samples. Twenty tests were conducted on M20 mix while ten tests were conducted 
on M30 mix. For M20 mix, tests have been conducted at four different minor principal stresses $\left(\sigma_{3}\right)$ of $2.5 \mathrm{MPa}, 5 \mathrm{MPa}, 7.5 \mathrm{MPa}$, and $10 \mathrm{MPa}$. The intermediate principal stress $\left(\sigma_{2}\right)$ had been kept such that the ratio between intermediate and minor principal stress was $1,1.5$, 2, 2.5 and 3. For M30 mix, $\sigma_{3}$ was kept at 5, 7.5 and $10 \mathrm{MPa}$ while $\sigma_{2}$ was kept such that the ratio of $\sigma_{2}$ and $\sigma_{3}$ was 1,2 , and 3. One test was conducted at $\sigma_{3}$ of $10 \mathrm{MPa}$ and $\sigma_{2}$ of $15 \mathrm{MPa}$ respectively. The results of experimental study on M20 concrete can be also found in Sajwan et al. (2016) where in the concrete has been considered as artificial rocks.

\subsection{Testing procedure}

The friction between the concrete surface and the loading platens affect the characteristic strength of concrete (Kupfer et al. 1969). A number of friction reducing measures have been discussed by Launay and Gachon (1972). For the present study, two layers of $0.25 \mathrm{~mm}$ thick Teflon sheet sandwiching a uniform layer of grease have been used as a friction reducing agent. The concrete sample wrapped with friction reducing agent was placed in the sample holder and the loading platens were touched to it. An initial seating stress of $1 \mathrm{MPa}$ was applied in all the three directions to make sure that the loading platens were in proper contact with the sample. The stress in all the three directions was then hydrostatically increased at a constant rate of $1 \mathrm{MPa} / \mathrm{min}$ till the all-around stress equal to $\sigma_{3}$ was reached. Now the stress in the $\mathrm{X}$ direction was maintained at the $\sigma_{3}$ value while stress from the $\mathrm{Y}$ and $\mathrm{Z}$ direction were further increased at the same rate till it reaches $\sigma_{2}$ value. Now the stress from Y direction was maintained at $\sigma_{2}$ value and the stress from $\mathrm{Z}$ direction was increased at the same rate till the failure.

Since the testing was conducted at stress controlled conditions, the post-peak behavior of concrete was not obtained. A sudden shooting of deformation in major principal stress direction was observed which indicated the failure of the sample. Once the failure of the 
sample was observed, the testing was stopped and the sample was carefully taken out from the sample holder and the details of the failure mode were noted.

\subsection{Experimental results}

\subsection{Uniaxial compression test results}

Five uniaxial compression tests were conducted for both M20 and M30 mix. The samples were of same size i.e. $100 \mathrm{~mm} \times 100 \mathrm{~mm} \times 100 \mathrm{~mm}$. The tests were conducted at the same stress rate of $1 \mathrm{MPa} / \mathrm{min}$. The average compressive strength observed for M20 mix was 24.39 $\mathrm{MPa}$, and for M30 mix it was $34.67 \mathrm{MPa}$. The average compressive strength of the mixes has been designated as the characteristic strength $\left(f_{c}\right)$ of concrete mix.

\subsection{True-triaxial compression test results}

Fig. 3 shows the typical failed sample and failure pattern for concrete under the truetriaxial compression testing. It was observed that many cracks have developed throughout the sample. The cracks propagated through the aggregate-mortar interface or through the mortar alone. The fracture plane was observed to have strike almost aligned with the plane of the intermediate principal stress $\left(\sigma_{2}\right)$. The dip of the fracture plane was oriented toward the direction of the minor principal stress $\left(\sigma_{3}\right)$. Similar failure pattern was also observed by previous researchers (He and Song 2010; Shang and Li 2014; Zhou et al. 2014).

In this study, we have assumed a positive sign convention for compression and negative sign convention for tension. The results of the true-triaxial tests in terms of the principal stresses $\left(\sigma_{1}, \sigma_{2}, \sigma_{3}\right)$ at failure have been presented in Table 5. It was observed that, the strength of concrete also depends upon the intermediate principal stress. For the range of $\sigma_{2}$ and $\sigma_{3}$ considered, the strength $\left(\sigma_{1}\right)$ increases with the increase in $\sigma_{2}$. Fig. 5 a and $\mathbf{b}$ show the failure stress (or major principal stress) as a function of the ratio of the intermediate to the minor 
principal stress, for both M20 and M30 mix. The increasing trend of strength is very clear. Few typical stress-strain plots for the true-triaxial testing are presented in Fig. 4.

\subsection{True-triaxial strength database for plain cement concrete}

An attempt has been made to collect all the available experimental strength data of the plain cement concrete subjected to true-triaxial states of stress. The authors have been able to identify fourteen such datasets from literature. Table 6 a and $\mathbf{b}$ shows the detail of the truetriaxial tests database conducted on plain concrete. The database consists of number of test data, characteristic strength $\left(f_{c}\right)$, range of minor principal stress, intermediate principal stress and major principal stress for all data set. The concrete classified into two categories namely the Normal Strength Concrete (NSC) having the characteristic strength less the $60 \mathrm{MPa}$ and the High Strength Concrete (HSC) having the characteristic strength greater than $60 \mathrm{MPa}$ and accordingly mentioned in Table $\mathbf{6}$ a and b. The complete detail of the strength database is presented in Appendix-I.

\subsection{Multiaxial strength criteria for concrete}

Strength criteria or failure models are developed to predict the strength of concrete under various state of stress. A number of strength criteria were developed in the past. A list of major multiaxial strength criteria is presented in the introduction section of this article. Most of these criteria were developed considering the shape of the failure surface in the deviatoric plane. The parameters associated with these criteria are calculated on the basis of some standard laboratory test conducted on the same concrete mix. The standard laboratory tests conducted for the calculation of criterion parameters are uniaxial tension tests, uniaxial compression tests, equal biaxial compression tests and triaxial compression tests in tensile and compression meridians. However, for the most of the projects in India, only the uniaxial compression tests are conducted on the cubical sample of concrete. The standard correlation 
217 between strength obtained from other standard laboratory test mentioned earlier and uniaxial

218 compression test was used to calculate the parameters associated with the strength criterion. A 219 strength criterion can be called robust if it can predict the strength under true-triaxial 220 conditions using the parameters obtained from the conventional technique with higher 221 accuracy.

Three failure criteria were selected and their predictive capabilities with respect to the database generated have been evaluated. The three strength criteria considered for the present study are the Drucker-Prager (DP) criterion (Drucker-Prager 1952), the Bresler-Pester (BP) criterion (Bresler-Pester 1958) and the Hsieh-Ting-Chen (HTC) criterion (Hsieh et al. 1982). These criteria are classified as two parameter, three parameter and four parameter criteria respectively. These criteria are chosen as they are relatively simple and most commonly used for structural analysis. The brief detail and the calculation of the value of parameters associated with these criteria are given hereunder.

\subsection{Drucker-Prager (DP) criterion}

Drucker and Prager (1952) presented a modification to the classical von-Mises criterion which can be said to be a smooth approximation of the Mohr-Coulomb hexagonal surface. The criterion can be presented as:

$$
f\left(I_{1} . J_{2}\right)=0
$$

or, $\quad \alpha I_{1}+\sqrt{J_{2}}-k=0$

where, $\alpha$ and $k$ are material constants or criterion parameters.

$I_{1}$ and $J_{2}$ are stress invariant defined as:

$$
I_{1}=\sigma_{1}+\sigma_{2}+\sigma_{3}
$$

$$
J_{2}=\frac{1}{6}\left[\left(\sigma_{1}-\sigma_{2}\right)^{2}+\left(\sigma_{2}-\sigma_{3}\right)^{2}+\left(\sigma_{3}-\sigma_{1}\right)^{2}\right]
$$

where, $\sigma_{1}, \sigma_{2}$ and $\sigma_{3}$ are major, intermediate and minor principal stress. 
241 The material constant or the criterion parameters associated with the strength criteria are

242 generally obtained by considering two failure states namely:

243 Uniaxial compressive strength: $\sigma_{3}=\sigma_{2}=0 ; \sigma_{1}=f_{c}$

$244 \quad$ Equal biaxial strength: $\sigma_{3}=0 ; \sigma_{1}=\sigma_{2}=f_{b c}$

Considering the standard correlation between equal biaxial strength and uniaxial compressive strength as:

$$
f_{b c}=1.15 \cdot f_{c}
$$

The value for the strength parameters are obtained as:

$$
\begin{aligned}
\alpha & =-0.0666 \\
\frac{k}{f_{c}} & =0.5107
\end{aligned}
$$

\subsection{Bresler-Pester (BP) criterion}

$o r, \frac{\tau_{o c t}}{f_{c}}=a-b \cdot \frac{\sigma_{o c t}}{f_{c}}+c \cdot\left(\frac{\sigma_{o c t}}{f_{c}}\right)^{2}$

$\sigma_{o c t}$ and $\tau_{o c t}$ are octahedral normal and shear stress defined as:

$$
\sigma_{o c t}=\frac{I_{1}}{3}
$$

$258 \quad$ and, $\quad \tau_{\text {oct }}=\sqrt{\frac{2}{3} J_{2}}$

The material constant or the criterion parameters associated with the strength criteria are generally obtained by considering three failure states namely:

$$
\text { Uniaxial tensile strength: } \sigma_{1}=\sigma_{2}=0 ; \sigma_{3}=-f_{t}
$$

$$
\text { Uniaxial compressive strength: } \sigma_{3}=\sigma_{2}=0 ; \sigma_{1}=f_{c}
$$

$$
\text { Equal Biaxial strength: } \sigma_{3}=0 ; \sigma_{1}=\sigma_{2}=f_{b c}
$$


Considering the standard correlation between equal biaxial strength, uniaxial tensile strength and uniaxial compressive strength as:

$$
f_{b c}=1.15 \cdot f_{c}
$$

and, $f_{t}=0.10 \bullet f_{c}$

The value for the strength parameters are obtained as:

$$
\begin{aligned}
& a=0.099 \\
& b=-1.532 \\
& c=-1.245
\end{aligned}
$$

\subsection{Hsieh-Ting-Chen (HTC) criterion}

Hsieh et al. (1982) presented a four-parameter criterion for concrete in the terms of stress invariant as:

$$
\begin{gathered}
f\left(I_{1} . J_{2}, \sigma_{1}\right)=0 \\
\text { or, } \quad a \frac{J_{2}}{f_{c}^{2}}+b \frac{\sqrt{J_{2}}}{f_{c}}+c \frac{\sigma_{1}}{f_{c}}+d \frac{I_{1}}{f_{c}}=1
\end{gathered}
$$

$$
\text { where, } a, b, c \text { and } d \text { are material constant or criterion parameters. }
$$

The material constant or the criterion parameters associated with the criterion are generally obtained by considering the three failure states namely:

$$
\text { Uniaxial tensile strength: } \sigma_{1}=\sigma_{2}=0 ; \sigma_{3}=-f_{t}
$$

$$
\text { Uniaxial compressive strength: } \sigma_{3}=\sigma_{2}=0 ; \sigma_{1}=f_{c}
$$

Equal Biaxial strength: $\sigma_{3}=0 ; \sigma_{1}=\sigma_{2}=f_{b c}$

$$
\text { Confined triaxial compression strength: } \sigma_{2}=\sigma_{3}=f_{p c} ; \sigma_{1}=f_{c c}
$$

Considering the standard correlation between equal biaxial strength, uniaxial tensile strength, confined compression strength and uniaxial compressive strength as:

$$
\begin{aligned}
& f_{b c}=1.15 \bullet f_{c} \\
& f_{t}=0.10 \bullet f_{c} \\
& f_{p c}=0.8 \bullet f_{c}
\end{aligned}
$$




$$
f_{c c}=4.2 \cdot f_{c}
$$

The value for the strength parameters can be obtained as:

$$
\begin{aligned}
& a=2.002 \\
& b=16.806 \\
& c=-9.128 \\
& d=-0.236
\end{aligned}
$$

The calculation for criterion parameter has been presented in appendix-II. Similar method for calculation of parameters associated with strength criterion was discussed by some previous researchers (Chen 2007; Labbane et al. 1993). The values of the parameters associated with criteria presented above will be mentioned as the model value of the parameters hereafter for further reference in this article.

\subsection{Analysis method}

Two different types of procedure for analysis have been considered in the present study. The first procedure compares the value of parameters associated with these criteria. The value of parameters obtained from the true-triaxial experimental study has been compared to the model values as obtained in the previous section. This analysis has been conducted for DP and BP criteria only as these can be represented easily in two dimensional space. The experimental data are plotted on the respective two dimensional spaces to obtain the experimental value of criterion parameters. A best fit line in the $\sqrt{J_{2}}-I_{1}$ space for the DP criterion and $\frac{\tau_{o c t}}{f_{c}}-\frac{\sigma_{o c t}}{f_{c}}$ space for the BP criterion can easily give the criterion parameters.

The second procedure calculates the value of major principal stress, $\sigma_{l}$ considering the model value of parameters. The error between the calculated and the experimental value of $\sigma_{l}$ has been used to determine the predictive capability of the strength criteria. A MATLAB program has been developed to calculate the value of $\sigma_{l}$. The predictive capability of the 
criteria was determined using three indices namely root mean square error (RMSE), coefficient of accordance (COA) and coefficient of determination $\left(\mathrm{R}^{2}\right)$.

Root mean square error (RMSE) was calculated as:

$$
R M S E=\sqrt{\frac{1}{n} \sum_{i=1}^{n}\left(\sigma_{1, i}^{c a l}-\sigma_{1, i}^{\exp }\right)^{2}}
$$

where $\sigma_{1, i}^{c a l}$ and $\sigma_{1, i}^{\text {exp }}$ are the calculated and the experimental value of the major principal stress for $i^{\text {th }}$ data respectively and ' $n$ ' is the number of data points.

Coefficent of accordance (COA) was calculated as

$$
\psi^{2}(C O A)=\frac{\sum\left(\sigma_{1, i}^{\exp }-\sigma_{1, i}^{c a l}\right)^{2}}{\sum\left(\sigma_{1, i}^{\exp }-\sigma_{1}^{a v g}\right)^{2}}
$$

where $\sigma_{1}^{\text {avg }}$ is average of experimental value of the major principal stress. RMSE and $\psi^{2}$ are the measure of goodness of prediction. The lower value of the RMSE and $\psi^{2}$ represents a better prediction. The coefficient of determination $\left(\mathrm{R}^{2}\right)$ was used to assess the scatter between the experimental and calculated value of $\sigma_{l}$ relative to the best fit line.

\subsection{Analysis results}

Figure 6 (a) to (d) show the plot for experimental results obtained for M20 and M30 mix in $\sqrt{J_{2}}-I_{1}$ space for the DP criterion and $\frac{\tau_{o c t}}{f_{c}}-\frac{\sigma_{o c t}}{f_{c}}$ space for BP criterion. The equation for the best fitting straight line for DP criterion and second order curve for BP criterion has been also shown. The experimental values of the parameters have been obtained from best fitting equation for the complete database and presented as Table $7 \mathbf{a}$ and $\mathbf{b}$. The absolute error and RMSE in prediction of the parameters is presented in the Table 8 a and b. For normal strength concrete, the RMSE in parameters associated with the DP criterion are 0.141 for $\alpha$ and 0.157 for $k / f_{c}$. For high strength concrete, the RMSE in parameters associated with DP criterion are 0.093 for $\alpha$ and 0.036 for $k / f_{c}$. Fig. 7 a and $\mathbf{b}$ shows the plot of the variation of 
the DP criterion parameter with respect to characteristic strength. A significant scatter can be observed clearly. Similarly, for normal strength concrete, the RMSE in parameters associated with the BP criterion are 0.193 for $\mathrm{a}, 0.798$ for $\mathrm{b}$ and 1.126 for $\mathrm{c}$. For high strength concrete, the RMSE in parameters associated with the BP criterion are 0.194 for $\mathrm{a}, 0.809$ for $\mathrm{b}$ and 1.084 for c. Fig. 8 a, $\mathbf{b}$ and $\mathbf{c}$ show the plot of the variation of the parameters with respect to the characteristic strength of concrete for the BP criterion.

Table 9 a and $\mathbf{b}$ shows the value of the various predictability indices obtained for all the sixteen data set considered in the present study using the second approach. Fig. 9 shows the plot of experimental to calculated value of the major principal stress obtained from the three criteria for both High Strength Concrete (HSC) and Normal Strength Concrete (NSC) concrete. It can be clearly seen from Table 9 a, that for NSC, overall HTC criterion shows the least error having RMSE of 19.345 and COA of 0.289 followed by DP criterion having RMSE of 33.837 and COA of 0.884 . For HSC, The DP criterion shows the least error with RMSE of 59.283 and COA of 1.142 followed by BP criterion having RMSE of 62.314 and COA of 1.262. Fig. 9 shows that the DP and BP criteria underestimate the major principal stress while the HTC criterion overestimates.

\section{Concluding remarks}

The paper discusses in details, the aspects related to the true-triaxial strength of plain cement concrete. A comprehensive true-triaxial testing program was conducted on two different mixes of concrete. Thirty tests were conducted and the result of experimental study along with that of published articles in literature have been used to quantitatively evaluate the three most commonly used strength criteria for concrete. Two different approaches were used to evaluate the criteria.

From the study, it was observed that the model value of the parameters obtained using standard correlations and failure states shows significant error compared to that obtained by 
fitting best fit line in DP and BP criteria space. This again significantly affects the overall predictive capability of the criteria. For the database considered in present study, it was also observed that for NSC, HTC criterion with model value of parameters shows the least error while for HSC, DP criterion shows the least error. Overall, BP and DP criterions underestimate while the HTC criterion overestimates.

Finally, it can be concluded from this study that very high error is associated with these criteria when used with the model values of the parameters. The experimental value of the parameters must be supplied to these criteria for better accuracy when used for numerical simulations. Thus, outlining that engineers must not rely only on uniaxial compressive strength/characteristic strength of concrete for designing and analyzing any concrete structure.

\section{Acknowledgement}

A part of this research was carried out from financial assistance obtained from NRDMS division, Department of science and technology, New Delhi through project number NRDMS/11/3067/014 (G). The authors duly acknowledge the financial assistance provided. The authors are grateful to the unknown reviewers for critically reviewing and suggesting improvements in the manuscript.

\section{References}

Ahmad, M. and Ajorloo, A. 2005. Experimental study of the mechanical behavior of plastic concrete in triaxial compression. Cement and Concrete Research. 35(2): 412-419.

Akroyd, T. N. W. 1961. Concrete under Triaxial Stress. Magazine of Concrete Research. 13(39): 111-118.

Balmer, G.G. 1949. Shearing strength of concrete under high triaxial stress-computation of Mohr's envelope as a Curve, US Department of the Interior and Bureau of Reclamation, Denver, USA, Structural Research Laboratory Report No. SP-23. 
BIS (Bureau of Indian Standards). 1990. IS 2386 (Part IV)-1963 (Reaffirmed 1990): Specification for Coarse and Fine Aggregates from Natural Sources for Concrete, Bureau of Indian Standards, New Delhi.

BIS (Bureau of Indian Standards). 2002. IS 383-1970 (Reaffirmed 2002): Specification for coarse and fine aggregates from natural sources for concrete, Bureau of Indian Standards, New Delhi.

BIS (Bureau of Indian Standards). 2005. IS 8112-1989 (Reaffirmed 2005): 43 Grade ordinary portland cement-Specification. Bureau of Indian Standards, New Delhi.

BIS (Bureau of Indian Standards). 2009. IS 10262-2009: Concrete Mix ProportioningGuidelines. Bureau of Indian Standards, New Delhi.

Bresler, B. and Pister, K.S. 1958. Strength of concrete under combined stresses. Journal of American Concrete Institute. 55: 321- 345.

Chen, W.F. 2007. Plasticity in reinforced concrete. Ross Publishing.

Chinn, J. and Zimmerman, R.M. 1965. Behavior of plain concrete under various high triaxial compression loading conditions. Colorado University at Boulder.

Drucker, D.C. and Prager, W. 1952. Soil mechanics and plasticity analysis of limit design. Quaterly of Applied Mechanics. 10: 157-165.

Gabet, T., Malécot, Y., and Daudeville, L. 2008. Triaxial behaviour of concrete under high stresses: Influence of the loading path on compaction and limit states. Cement and Concrete Research, 38(3): 403-412.

Gerstle, K.H., Aschl, H., Bellotti, R., Bertacci, P., Kotsovos, M.D., Ko, H.Y., Linse, D., Newman, J. B., Rossi, P., Schickert, G., Tylor, M. A., Traina, L.A., Winkler, H. and Zimmermann R.M. 1980. Behavior of concrete under multiaxial stress states, Journal and Engineering Mechanics. ASCE, 106(6): 1383-1403. 
Hampel, T., Speck, K., Scheerer, S., Ritter, R., and Curbach, M. 2009. High-performance concrete under biaxial and triaxial loads. Journal of engineering mechanics, ASCE 135(11): 1274-1280.

He, Z.J., and Song, Y.P. 2010. Triaxial strength and failure criterion of plain high-strength and high-performance concrete before and after high temperatures, Cement and Concrete Research. 40(1): 171-178.

Hsieh, S.S., Ting, E.C. and Chen, W.F. 1982. A plastic-fracture model for concrete. International Journal of Solids and Structures. 18: 181-197.

Imran, I. and Pantazopoulou, S.J. 1969. Experimental study of plain concrete under triaxial stress. ACI Material Journal. 93(6): 589-601.

Kosaka, Y., Tanigawa, Y. and Hatanaka, S. 1984. Inelastic Deformational Behavior of Axially Loaded Concrete under Low Lateral Confining Stresses. Transaction of Japaneese Concrete Institute 6(III-5-B): 263-270.

Kotsovos, M.D. and Newman, J.B. 1978. Generalized stress-strain relation for concrete. Journal of Engineering Mechanics. 104(4): 845-856.

Kupfer, H. and Hilsdorf, H.K. and Rush, H. 1969. Behavior of concrete under biaxial stresses. Journal of American Concrete Institute. 66(8): 656-666.

Labbane, M., Saha, N.K. and Ting, E.C. 1993. Yield criterion and loading function for concrete plasticity. International Journal of Solids and Structure. 30(9): 1269-1288.

Launay, P. and Gachon, H. 1972. Strain and ultimate strength of concrete under triaxial stress. Concrete for Nuclear Reactors, American Concrete Institute, Special publication - 34: $112-121$

Li, Q. and Ansari, F. 1999. Mechanics of damage and constitutive relationships for highstrength concrete in triaxial compression. Journal of Engineering Mechanics. 125(1): 110. 
Liu, H.Y. and Song, Y.P. 2010. Experimental study of lightweight aggregate concrete under multiaxial stresses. Journal of Zhejiang University. SCIENCE A, 11(8): 545-554.

Malecot, Y., Daudeville, L., Dupray, F., Poinard, C., and Buzaud, E. 2010. Strength and damage of concrete under high triaxial loading. European Journal of Environmental and Civil Engineering, 14(6-7): 777-803.

Michelis, P. 1985. A true triaxial cell for low and high pressure experiments. International Journal of Rock Mechanics and Mining Science and Geomechanics Abstract. 22(3): $183-188$.

Mills, L.L. and Zimmerman, R.M. 1970. Compressive strength of plain concrete under multiaxial loading conditions. ACI Material Journal. 802-807.

Ottosen, N.S. 1975. Failure and elasticity of concrete (No. RISO-M--1801). Danish Atomic Energy Commission.

Petkovski, M., Crouch, R.S., and Waldron, P. 2006. Apparatus for testing concrete under multiaxial compression at elevated temperature (mac 2T). Experimental mechanics, 46(3): 387-398.

Petkovski, M., and Crouch, R.S. 2008. Strains under transient hygro-thermal states in concrete loaded in multiaxial compression and heated to $250 \mathrm{C}$. Cement and Concrete Research, 38(4): 586-596.

Petkovski, M. 2010. Effects of stress during heating on strength and stiffness of concrete at elevated temperature. Cement and Concrete Research, 40(12): 1744-1755.

Petkovski, M. 2012. Experimental detection of damage evolution in concrete under multiaxial compression. Journal of Engineering Mechanics, ASCE, 139(5): 616-628.

Reimann, H. 1965. Kritische Spannungszustände des Betons bei mehrachsiger, ruhender Kurzzeitbelastung. 
Sfer, D., Carol, I., Gettu, R. and Etse, G. 2002. Study of the behavior of concrete under triaxial compression. Journal of Engineering Mechanics. 128(2): 156-163.

Shang, H.S. and Ji, G.J. 2014. Mechanical behavior of different types of concrete under multiaxial compression. Magazine of Concrete Research. 66(17): 870-876.

Smith, S.S., Willam, K.J., Gerstle, K.H., and Sture, S. 1989. Concrete over the top--or, is there life after peak?. ACI-Materials Journal, 86(5): 491-497.

Van Mier, J. G. M. 1986. Fracture of concrete under complex stresses. Heron 31(3): 1-89.

Vu, X.D., Briffaut, M., Malecot, Y., Daudeville, L., and Ciree, B. 2015. Influence of the saturation ratio on concrete behavior under triaxial compressive loading. Science and Technology of Nuclear Installations, Vol. 2015, Article ID 976387.

Vu, X.H., Malecot, Y., Daudeville, L., and Buzaud, E. 2009. Experimental analysis of concrete behavior under high confinement: Effect of the saturation ratio. International Journal of Solids and Structures, 46(5): 1105-1120.

Vu, X.H., Malecot, Y., Daudeville, L., and Buzaud, E. 2009. Effect of the water/cement ratio on concrete behavior under extreme loading. International Journal for Numerical and Analytical Methods in Geomechanics, 33(17): 1867-1888.

Vu, X.H., Daudeville, L., and Malecot, Y. 2011. Effect of coarse aggregate size and cement paste volume on concrete behavior under high triaxial compression loading. Construction and Building Materials, 25(10): 3941-3949.

Wang, C.Z., Guo, Z.H. and Zhang, X.Q. 1987. Experimental investigation of biaxial and triaxial compressive concrete strength. ACI Material Journal. 84: 92-100.

Wastiels, J. 1979. Behaviour of concrete under multiaxial stresses-a review. Cement and Concrete Research. 9: 35-44. 
Willam, K.J. and Warnke, E.P. 1975. Constitutive models for the triaxial behavior of concrete. Proceedings, International association for bridge and structural engineering, 19, ISMES, Bergamo, Italy, pp. 174-175.

Zhou, J., Pan, J., Leung, C.K.Y. and Li, Z. 2014. Experimental study on mechanical behavior of high performance concrete under multi-axial compressive stress. Science China. Technology Science. 57(12): 2514-2522.

\section{List of Figures}

\begin{tabular}{|c|c|}
\hline Fig. 1 & True-triaxial Testing Machine at IIT Roorkee \\
\hline Fig. 2 & Sample Holder \\
\hline Fig. 3 & Typical Failed Sample and failure mode in concrete for the polyaxial test \\
\hline Fig. 4 & $\begin{array}{l}\text { Typical stress-strain plot for the true-triaxial test (Values in the box are in order of: } \\
\left.\sigma_{1}, \sigma_{2}, \sigma_{3}\right)\end{array}$ \\
\hline Fig. 5 & $\begin{array}{l}\text { Plot for Major Principal stress }(\sigma 1) \text { vs ratio of intermediate to minor principal stress } \\
\left(\sigma_{2} / \sigma_{3}\right) \\
\text { (a) For M20 Mix } \\
\text { (b) For M30 Mix }\end{array}$ \\
\hline Fig. 6 & $\begin{array}{l}\text { Plot for M20 and M30 Mix data in BP and DP criterion space } \\
\text { (a) For M20 Mix (BP) } \\
\text { (b) For M30 Mix (BP) } \\
\text { (c) For M20 Mix (DP) } \\
\text { (d) For M30 Mix (DP) }\end{array}$ \\
\hline Fig. 7 & Plot for experimental value and model value of DP criterion parameter \\
\hline Fig. 8 & Plot for experimental value and model value of BP criterion parameter \\
\hline Fig.9 & $\begin{array}{l}\text { Plot for calculated value and experimental values of major principal stress for all } \\
\text { criteria }\end{array}$ \\
\hline
\end{tabular}


List of Tables

\begin{tabular}{|c|c|}
\hline Table 1 & List of commonly used failure criterion for concrete \\
\hline Table 2 & Physical Property of Portland cement \\
\hline Table 3 & Physical Property of course aggregate and Fine aggregate \\
\hline Table 4 & Mix proportion for concrete \\
\hline Table 5 & Results of true-triaxial testing \\
\hline Table 6 & $\begin{array}{l}\text { (a) Available database of true-triaxial compression test conducted on plain } \\
\text { concrete (Normal Strength Concrete, NSC) } \\
\text { (b) Available database of true-triaxial compression test conducted on plain } \\
\text { concrete (High Strength Concrete, HSC) }\end{array}$ \\
\hline Table 7 & $\begin{array}{l}\text { (a) Calculation of criterion parameters for experimental data present in literature } \\
\text { (Normal Strength concrete, NSC) } \\
\text { (b) Calculation of criterion parameters for experimental data present in literature } \\
\text { (High Strength concrete, HSC) }\end{array}$ \\
\hline Table 8 & $\begin{array}{l}\text { (a) Error in prediction of criterion parameters for experimental data present in } \\
\text { literature (Normal Strength concrete, NSC) } \\
\text { (b) Error in prediction of criterion parameters obtained from experimental data } \\
\text { (High Strength concrete, HSC) }\end{array}$ \\
\hline Table 9 & $\begin{array}{l}\text { (a) Predictability indices for various criteria for Normal Strength Criterion (NSC) } \\
\text { (b) Predictability indices for various criteria for High Strength Criterion (HSC) }\end{array}$ \\
\hline
\end{tabular}




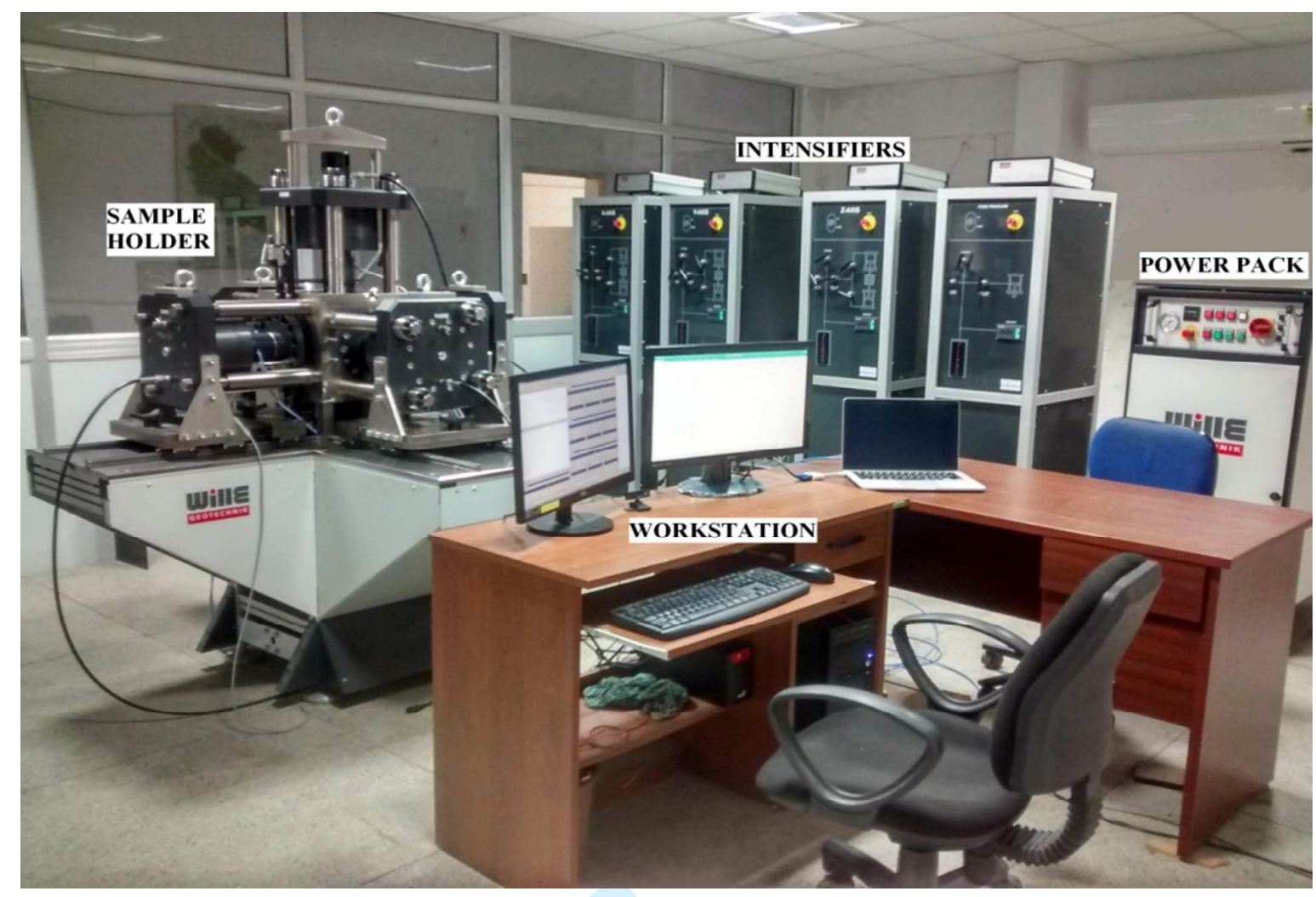

Figure 1. True-triaxial Testing Machine at IIT Roorkee 


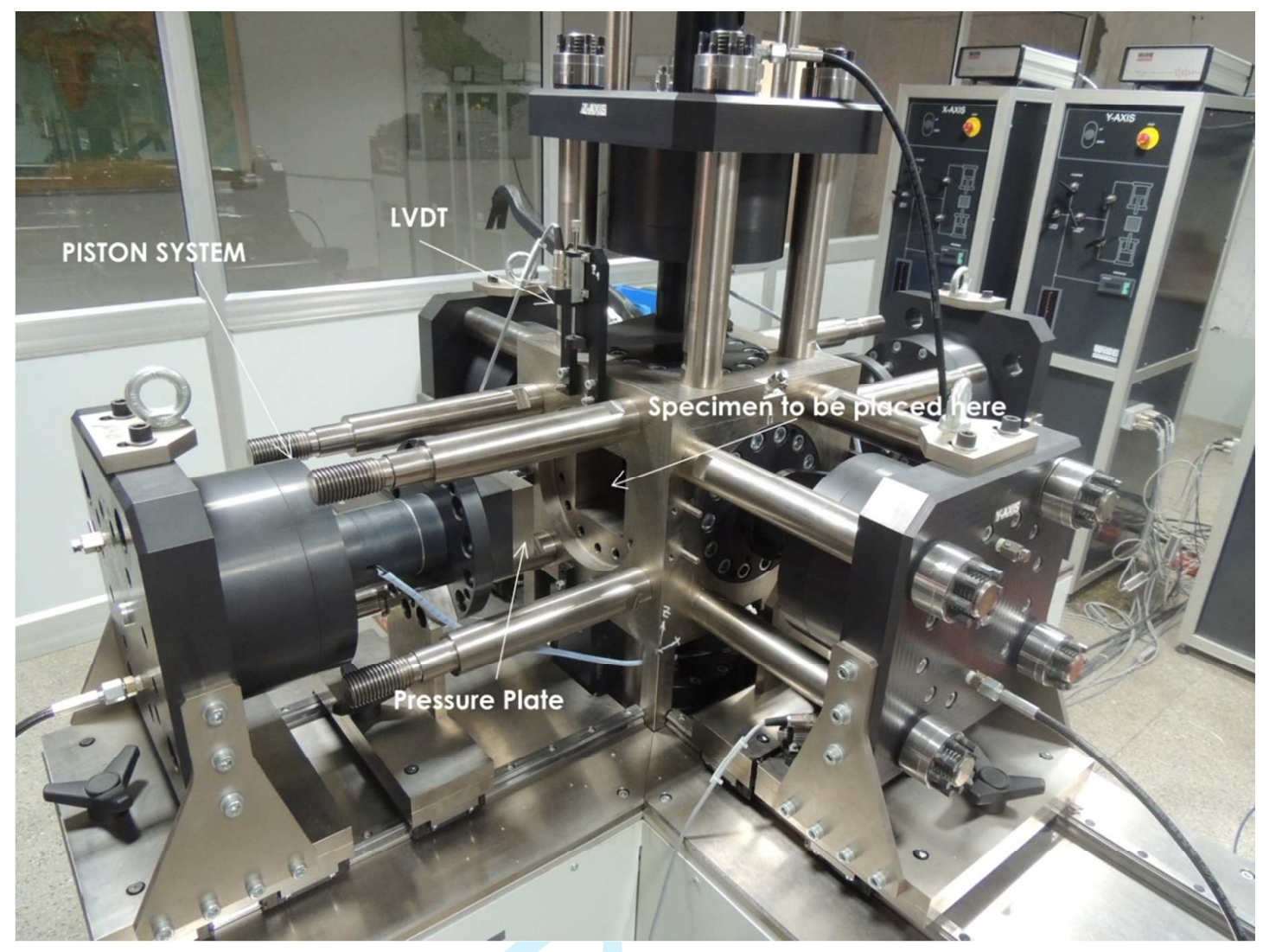

Figure 2. Sample Holder 

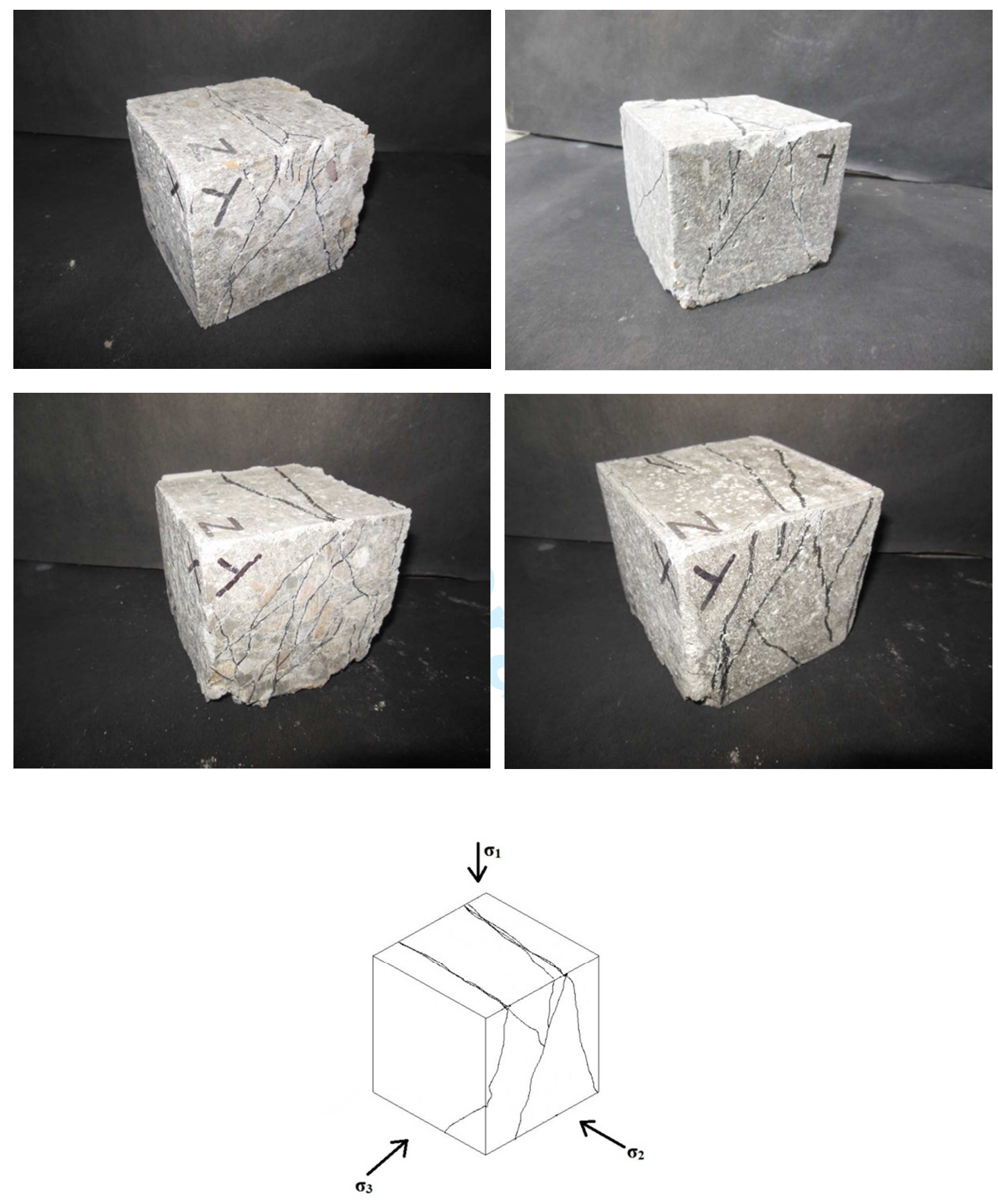

Figure 3. Typical Failed Specimen and failure mode in concrete for the polyaxial test 


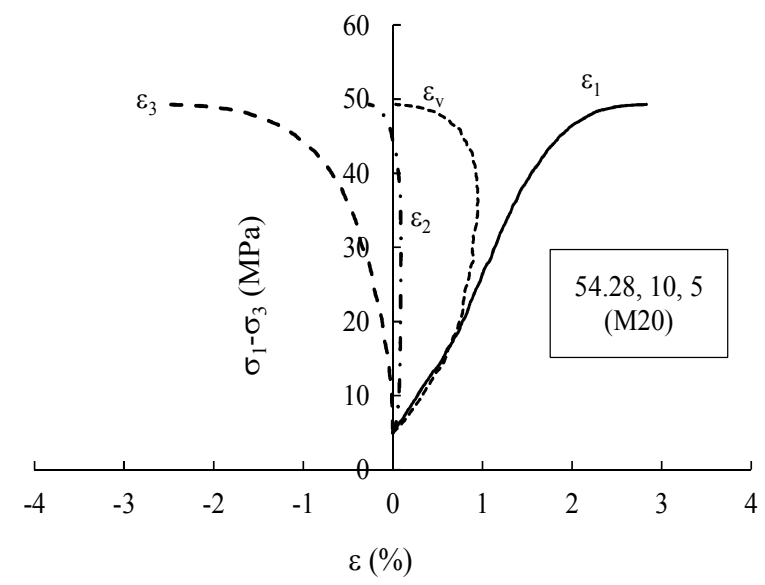

(a)

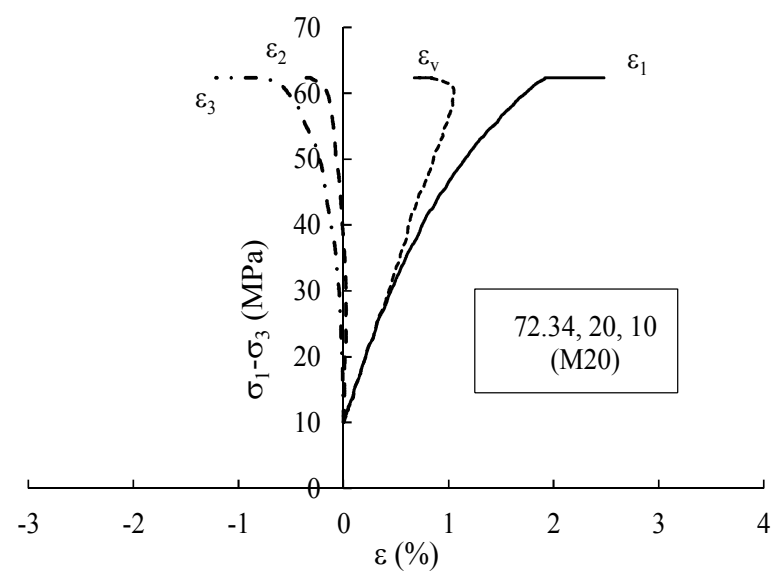

(c)

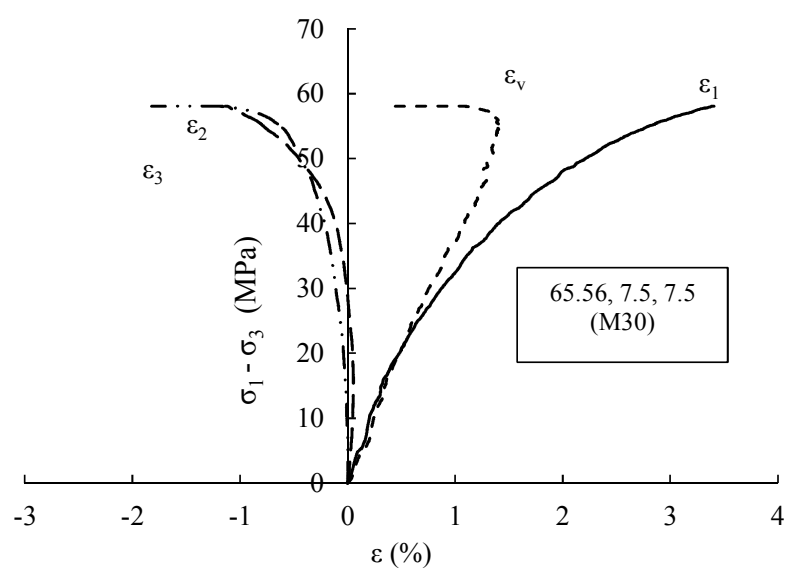

(e)

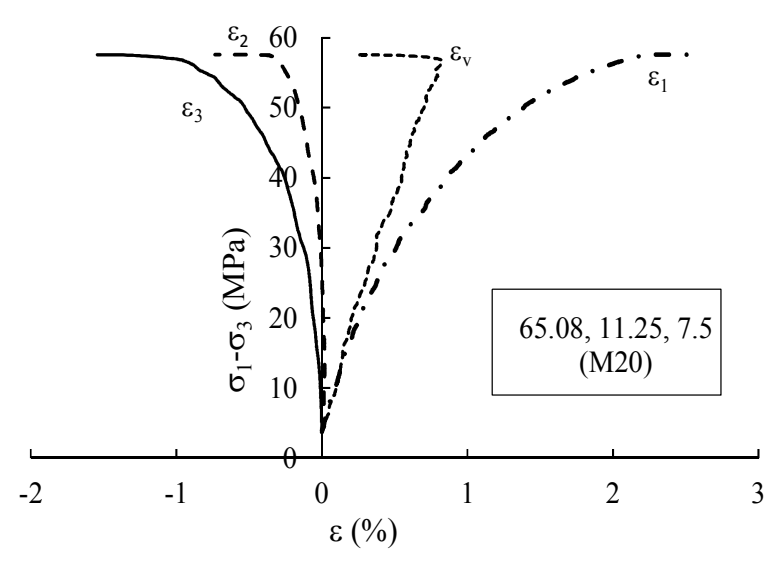

(b)

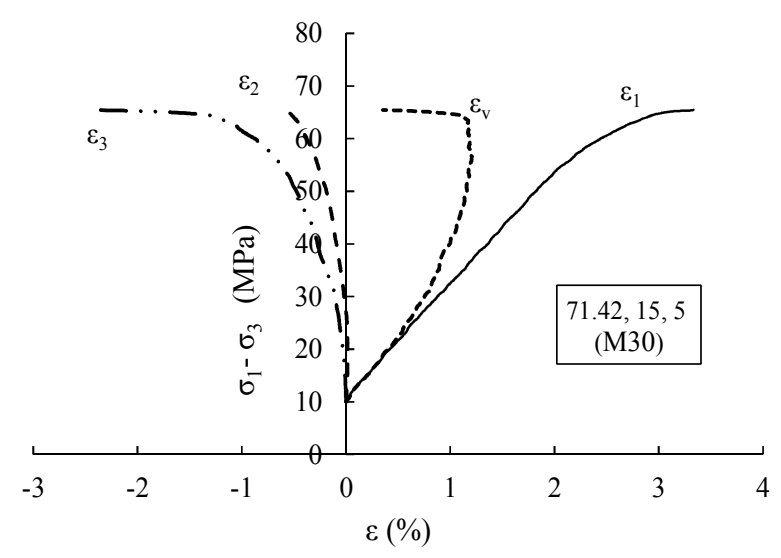

(d)

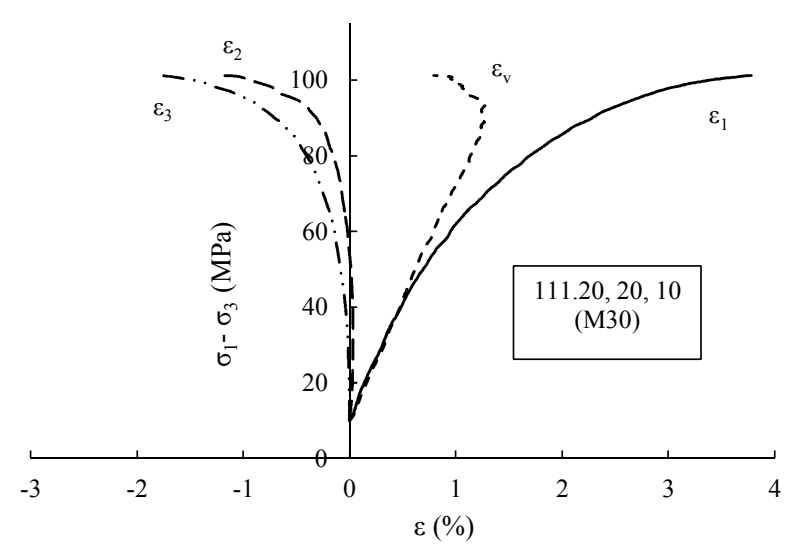

(f)

Figure 4. Typical stress-strain plot for the true-triaxial test (Values in the box are in order of : $\sigma_{1}, \sigma_{2}, \sigma_{3}$ ) 


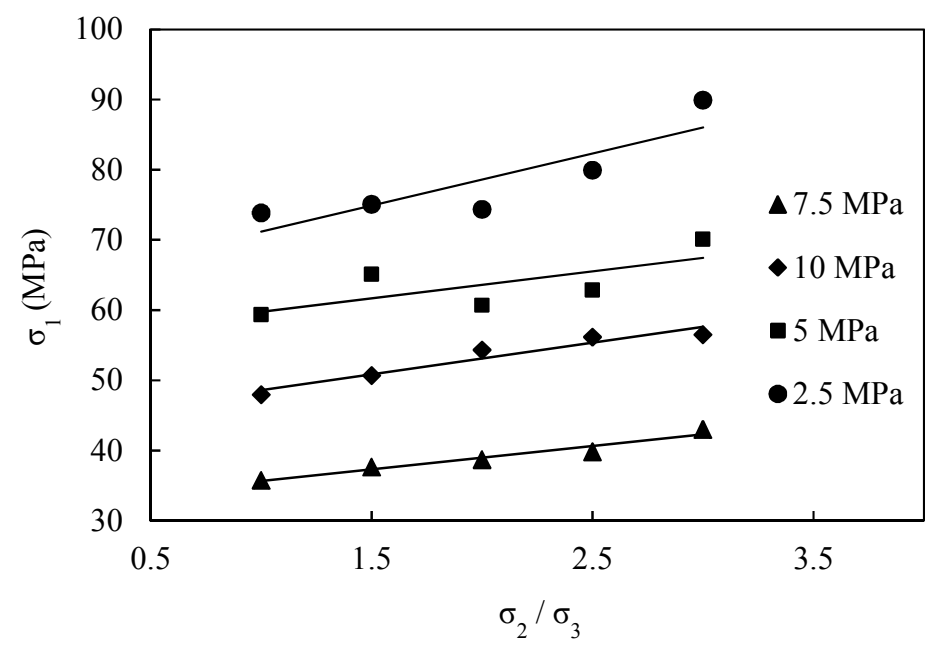

(a) For M20 Mix

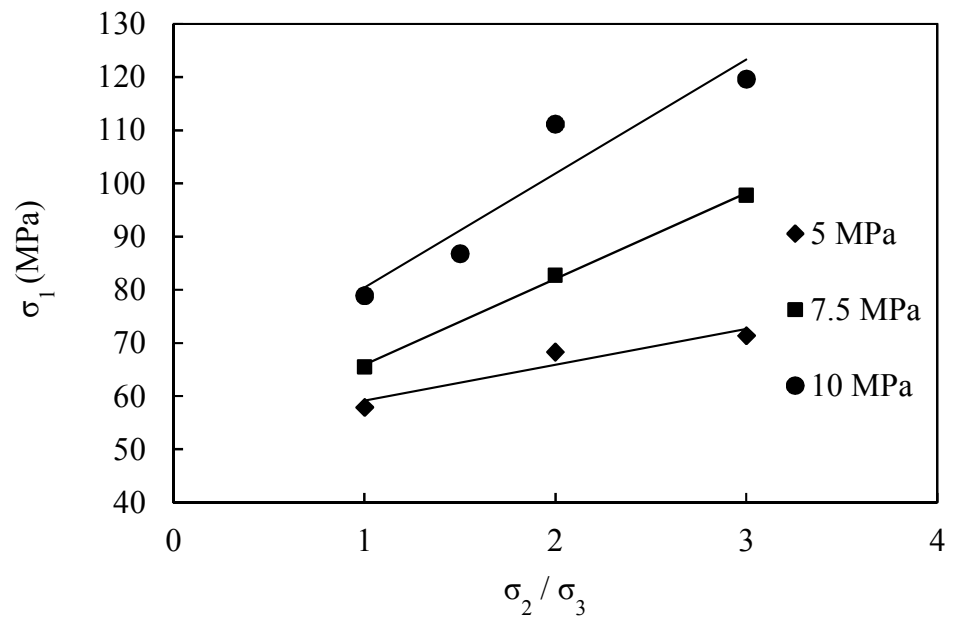

(b) For M30 Mix

Figure 5. Plot for Major Principal stress $\left(\sigma_{1}\right)$ vs. ratio of intermediate to minor principal stress $\left(\sigma_{2} / \sigma_{3}\right)$ 


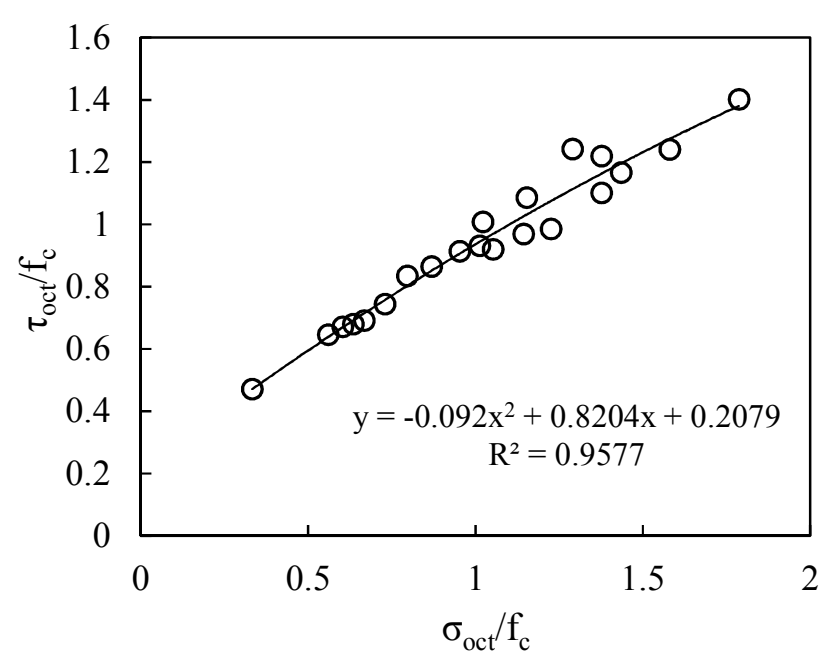

(a) For M20 Mix (BP)

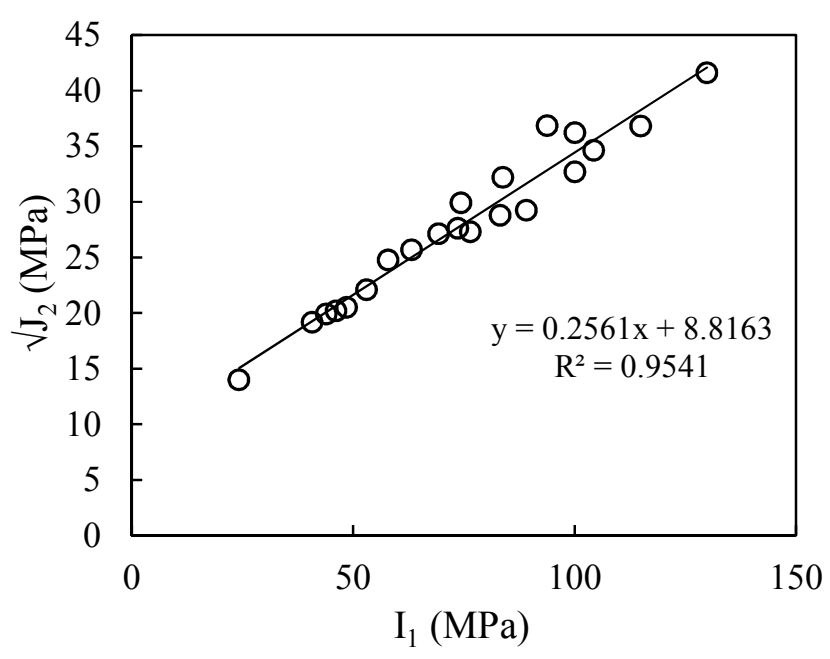

(c) For M20 Mix (DP)

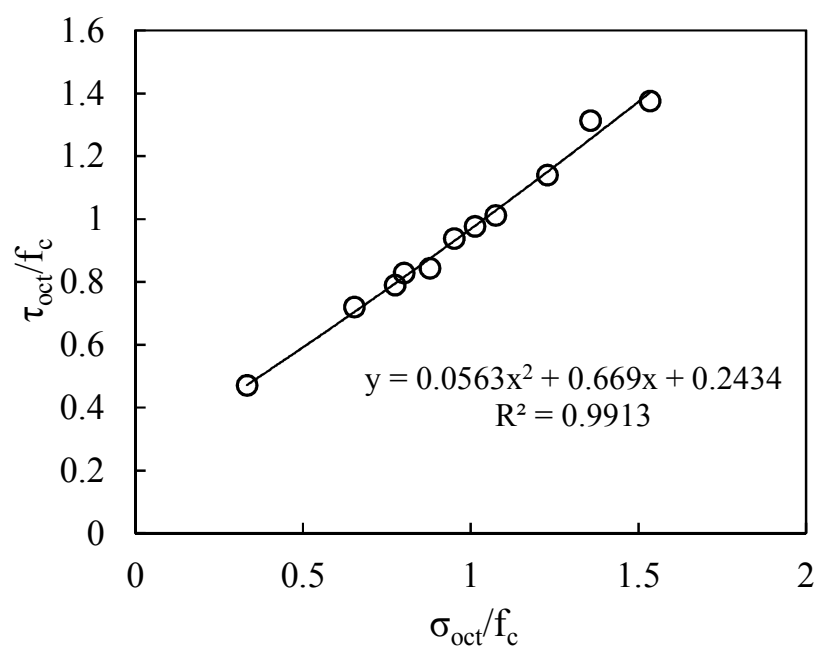

(b) For M30 Mix (BP)

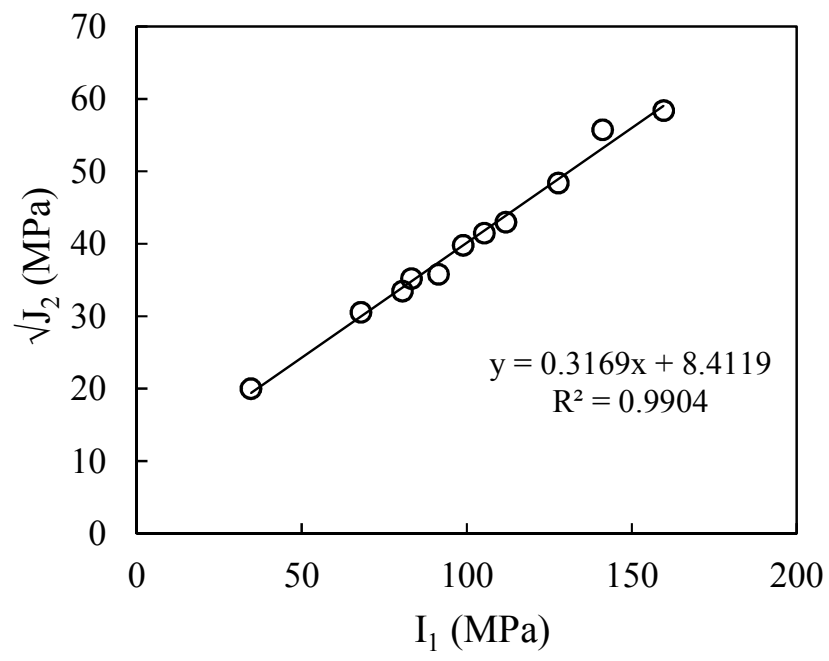

(d) For M30 Mix (DP)

Figure 6. Plot for M20 and M30 Mix data in the BP and DP criterion space 


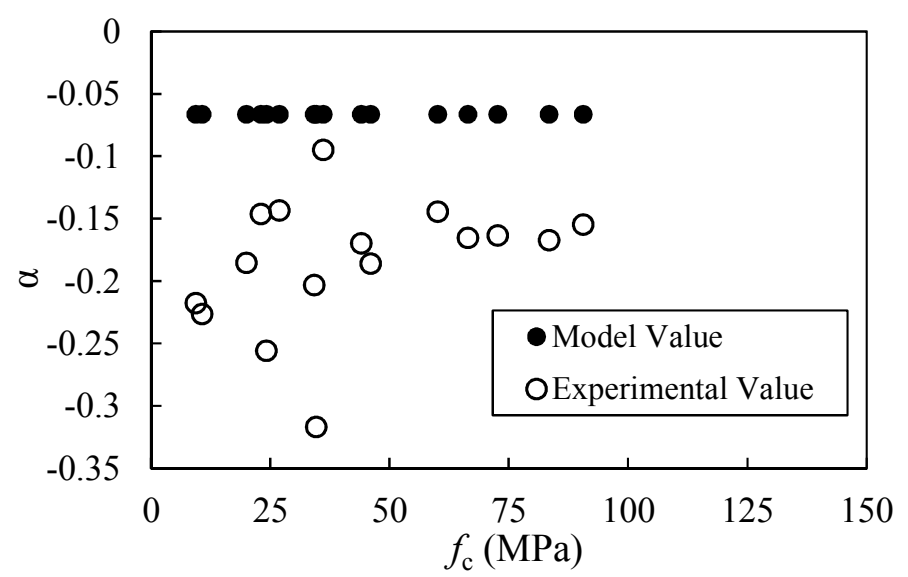

(a)

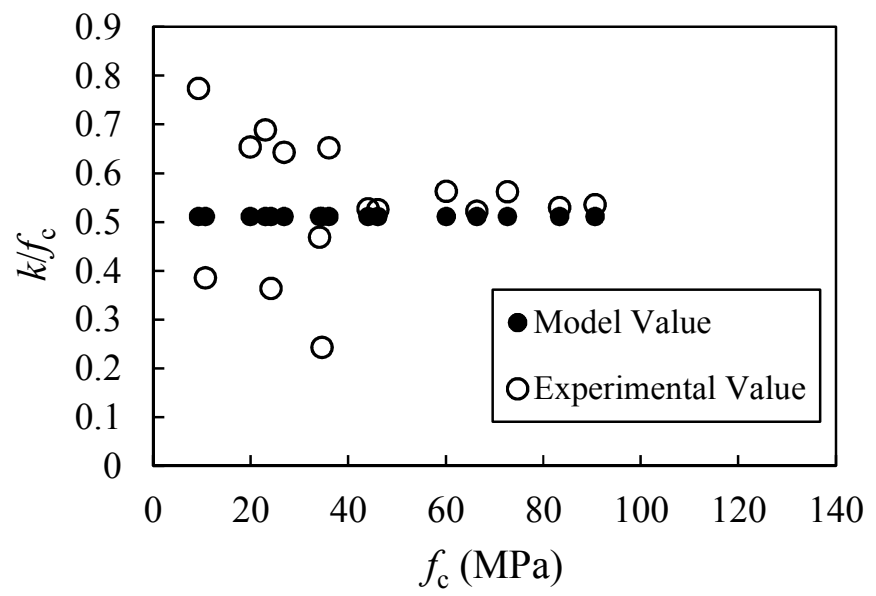

(b)

Figure 7. Plot for experimental value and model value of DP criterion parameter 


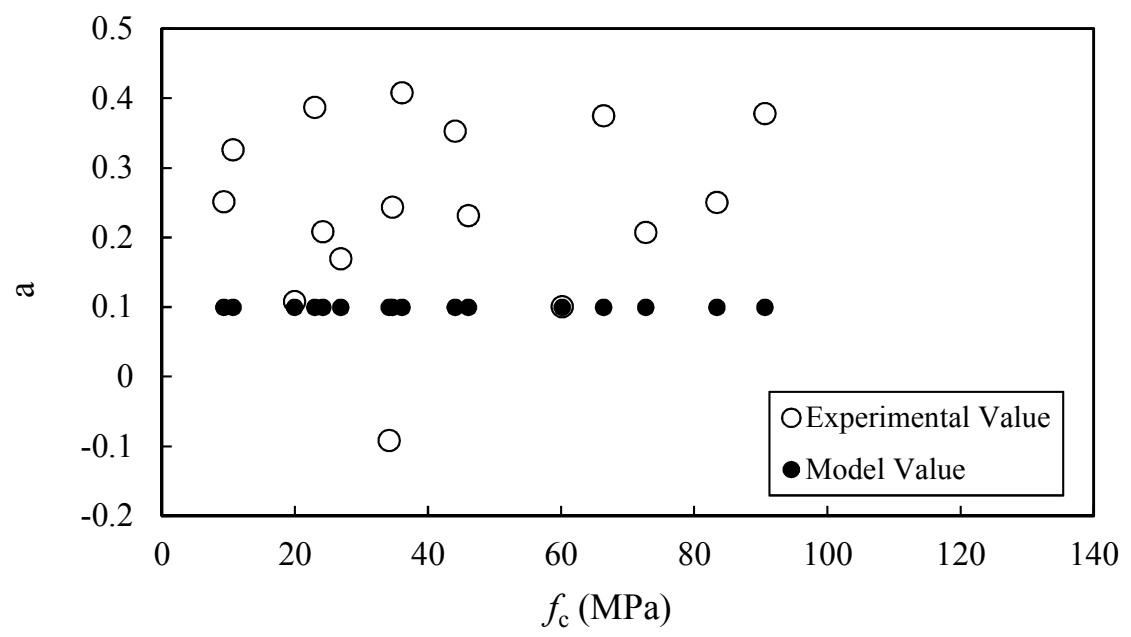

(a)

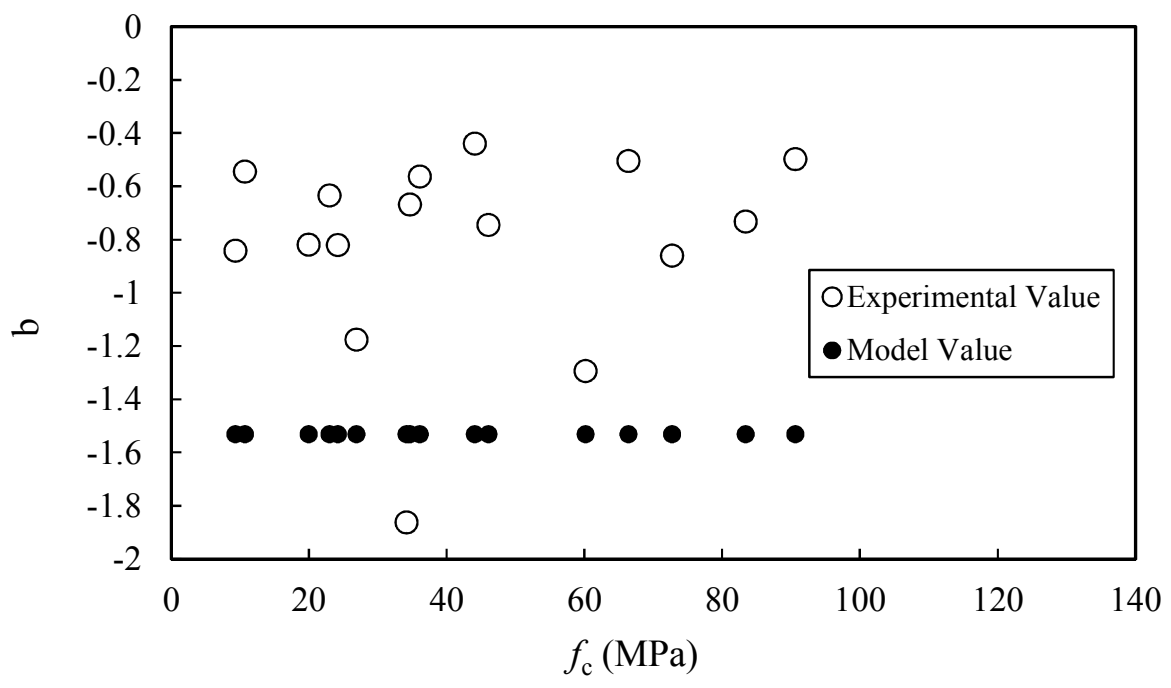

(b)

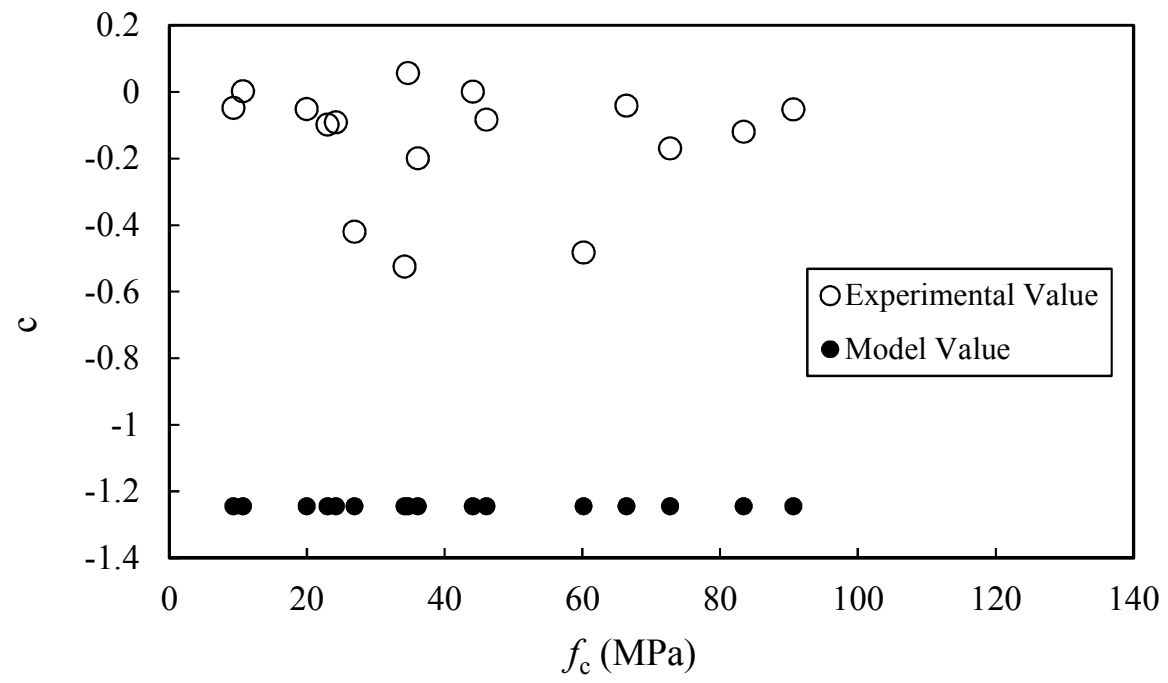

(c)

Figure 8. Plot for experimental value and model value of BP criterion parameter https://mc06.manuscriptcentral.com/cjce-pubs 


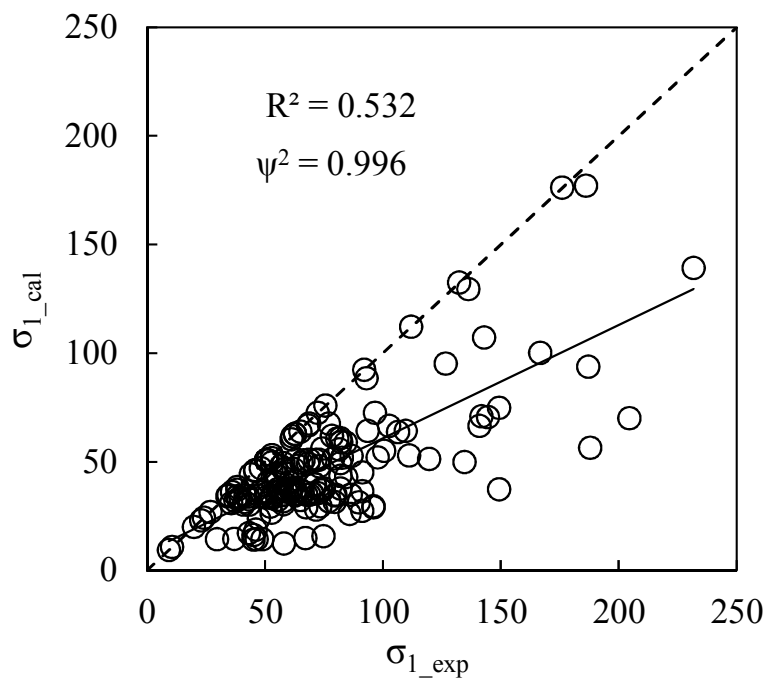

(a) Bresler-Pester Criterion for NSC

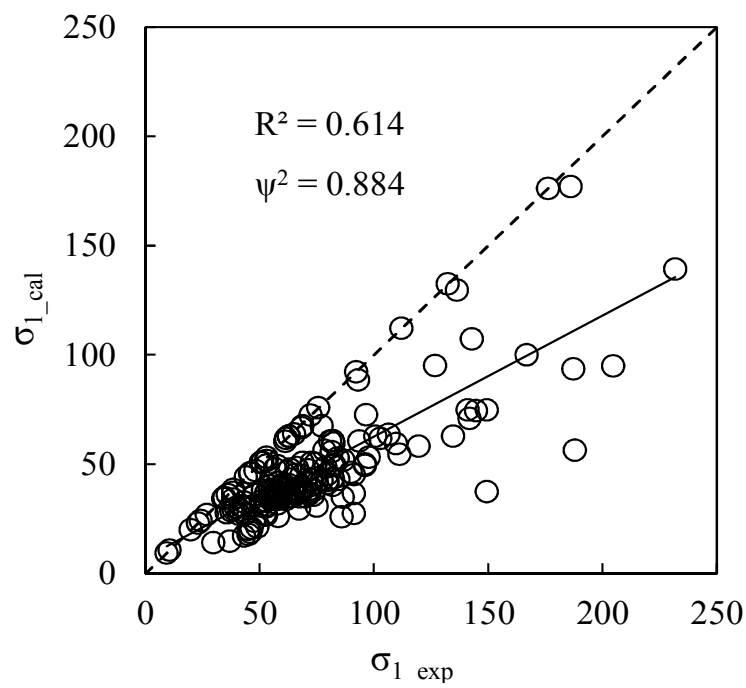

(c) Drucker-Prager Criterion for NSC

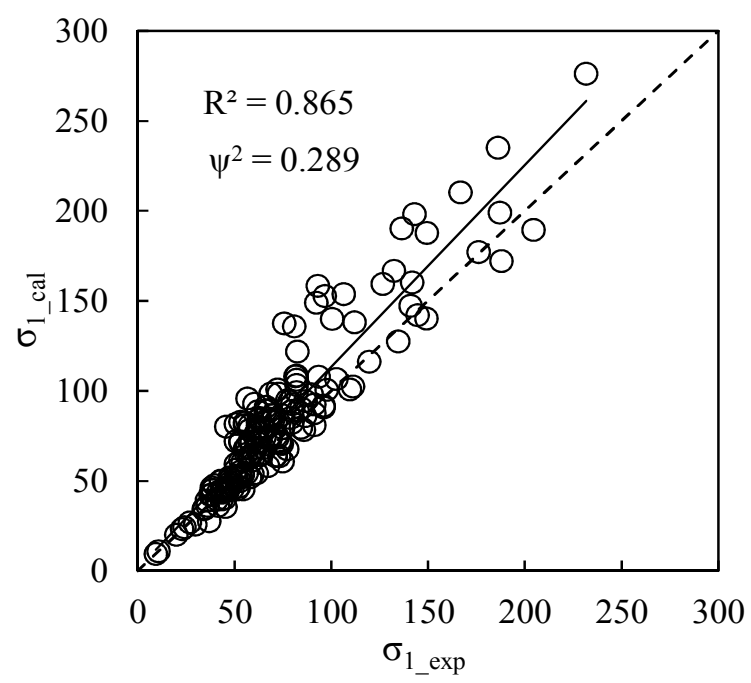

(e) Hsieh-Ting-Chen criterion for NSC

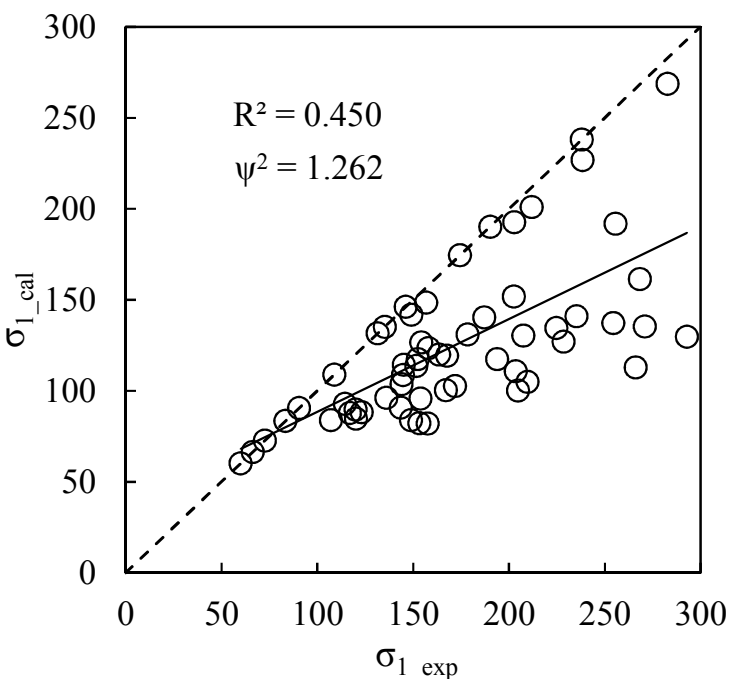

(b) Bresler-Pester Criterion for HSC

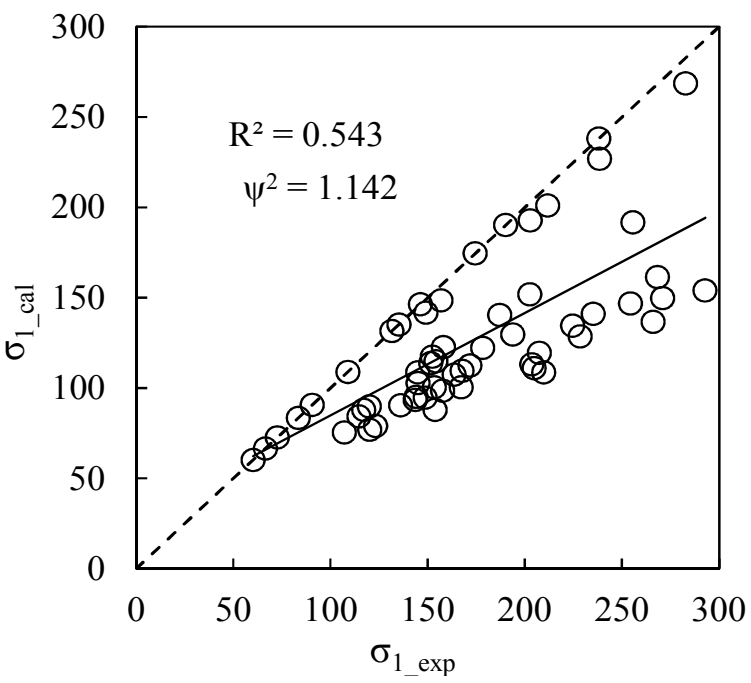

(d) Drucker-Prager Criterion for HSC

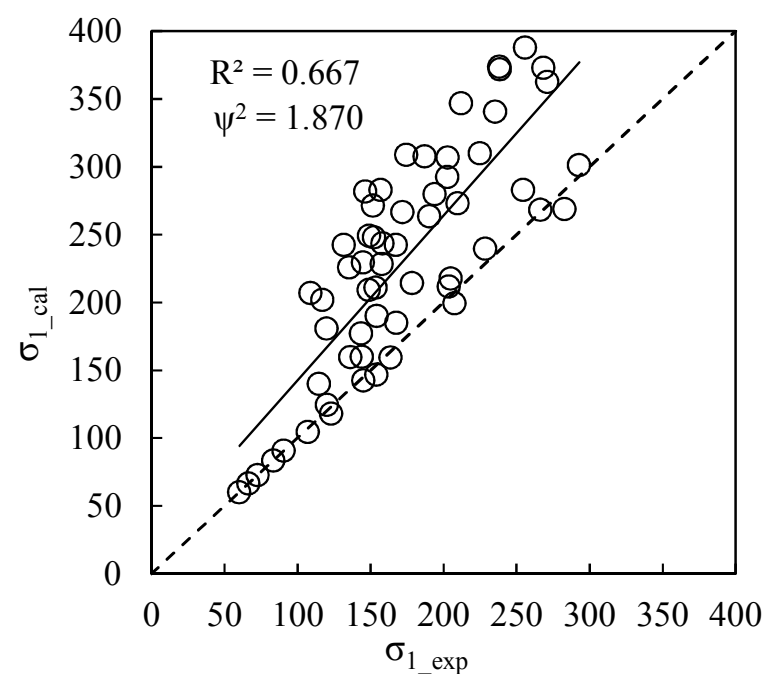

(f) Hsieh-Ting-Chen criterion for HSC

Figure 9. Plot for calculated value and experimental values of major principal stress for all criteria 
Table 1: List of commonly used failure criterion for concrete

\begin{tabular}{ccc}
\hline $\begin{array}{c}\text { Sl. } \\
\text { No. }\end{array}$ & Classification of criteria & Name of criteria \\
\hline 1 & Single Parameter criteria & Rankine \\
& & Tresca \\
& & Von Mises \\
\hline 2 & Double Parameter criteria & Mohr-Coulomb \\
& & Drucker-Prager \\
\hline 3 & Three Parameter criteria & Bresler-Pester \\
& & William Warnke \\
\hline 4 & Four Parameter Criteria & Ottosen \\
& & Reimann \\
& & Hsieh-Ting-Chen \\
\hline 5 & Five Parameter Criteria & Extended Version of William \\
& & Warnke \\
\hline
\end{tabular}


Table 2: Physical Property of Portland cement

\begin{tabular}{cccc}
\hline Physical Property & $\begin{array}{c}\text { IS 8112: 1989, 2005 } \\
\text { requirement }\end{array}$ & Test results & Units \\
\hline Blaine's fineness & $\geq 2250$ & 2900 & $\mathrm{Cm}^{2} / \mathrm{g}$ \\
Relative Density & - & 3.12 & - \\
Soundness (Le Chatelier's & $\leq 10$ & 3.14 & $\mathrm{~mm}$ \\
method) & $\leq 0.80$ & 0.12 & $\%$ \\
Autoclave expansion & $\geq 30$ & & $\mathrm{Min}$ \\
Setting time & $\leq 600$ & 54 & \\
Initial & & 215 & $\mathrm{MPa}$ \\
Final & $\geq 23$ & & \\
Compressive strength & $\geq 33$ & 36.92 & \\
3-days & & 45.76 & \\
7-days & & & \\
28-days & & & \\
& & & \\
\end{tabular}


Table 3: Physical Property of course aggregate and Fine aggregate

\begin{tabular}{ccc}
\hline Physical Property & Course Aggregate & $\begin{array}{c}\text { Fine } \\
\text { Aggregate }\end{array}$ \\
\hline Maximum Size (mm) & 12.5 & 4.75 \\
Relative Density & 2.64 & 2.67 \\
Water Absorption (\%) & 1.10 & 1.2 \\
Fineness Modulus & 6.35 & 2.65 \\
Impact value (\%) & 15.9 & - \\
Crushing Value (\%) & 21.2 & - \\
\hline
\end{tabular}


Table 4: Mix proportion for concrete

\begin{tabular}{ccccc}
\hline Mix ID & \multicolumn{4}{c}{ Ingredient $\left(\mathbf{k g} / \mathbf{m}^{\mathbf{3}}\right)$} \\
\cline { 2 - 5 } & Cement & Course Aggregate & Fine Aggregate & Water \\
\hline M20 & 336 & 890 & 946 & 221 \\
M30 & 380 & 935 & 894 & 207 \\
\hline
\end{tabular}


Table 5: Results of true triaxial testing

\begin{tabular}{|c|c|c|c|c|c|}
\hline Mix ID & $\begin{array}{c}\sigma_{1} \\
(\mathrm{MPa})\end{array}$ & $\begin{array}{c}\sigma_{2} \\
(\mathrm{MPa})\end{array}$ & $\begin{array}{c}\sigma_{3} \\
(\mathrm{MPa})\end{array}$ & $\begin{array}{c}I_{1} \\
\text { (MPa) }\end{array}$ & $\begin{array}{c}\sqrt{J_{2}} \\
\text { (MPa) }\end{array}$ \\
\hline \multirow[t]{10}{*}{ M30 } & 57.95 & 5 & 5 & 67.95 & 30.57 \\
\hline & 68.31 & 10 & 5 & 83.31 & 35.20 \\
\hline & 71.42 & 15 & 5 & 91.42 & 35.81 \\
\hline & 65.56 & 7.5 & 7.5 & 80.56 & 33.52 \\
\hline & 82.79 & 15 & 7.5 & 105.29 & 41.47 \\
\hline & 97.80 & 22.5 & 7.5 & 127.8 & 48.39 \\
\hline & 78.96 & 10 & 10 & 98.96 & 39.81 \\
\hline & 86.82 & 15 & 10 & 111.82 & 42.98 \\
\hline & 111.20 & 20 & 10 & 141.20 & 55.77 \\
\hline & 119.67 & 30 & 10 & 159.67 & 58.41 \\
\hline \multirow[t]{20}{*}{ M20 } & 35.74 & 2.5 & 2.5 & 40.74 & 19.19 \\
\hline & 37.62 & 3.75 & 2.5 & 43.87 & 19.93 \\
\hline & 38.65 & 5.0 & 2.5 & 46.15 & 20.19 \\
\hline & 39.77 & 6.25 & 2.5 & 48.52 & 20.52 \\
\hline & 43.00 & 7.5 & 2.5 & 53 & 22.08 \\
\hline & 47.92 & 5 & 5 & 57.92 & 24.78 \\
\hline & 50.66 & 7.5 & 5 & 63.16 & 25.67 \\
\hline & 54.28 & 10 & 5 & 69.28 & 27.12 \\
\hline & 56.16 & 12.5 & 5 & 73.66 & 27.63 \\
\hline & 48.43 & 15 & 5 & 76.48 & 27.30 \\
\hline & 59.33 & 7.5 & 7.5 & 74.33 & 29.92 \\
\hline & 65.08 & 11.25 & 7.5 & 83.83 & 32.22 \\
\hline & 56.67 & 15 & 7.5 & 83.17 & 28.78 \\
\hline & 60.67 & 18.75 & 7.5 & 89.07 & 29.24 \\
\hline & 70.11 & 22.5 & 7.5 & 100.11 & 32.69 \\
\hline & 73.82 & 10 & 10 & 93.82 & 36.85 \\
\hline & 74.06 & 15 & 10 & 100.06 & 36.20 \\
\hline & 72.33 & 20 & 10 & 104.33 & 34.62 \\
\hline & 73.93 & 25 & 10 & 114.93 & 36.82 \\
\hline & 89.91 & 30 & 10 & 129.91 & 41.58 \\
\hline
\end{tabular}


Table 6 a: Available database of true-triaxial compression test conducted on plain concrete (Normal Strength Concrete, NSC)

\begin{tabular}{|c|c|c|c|c|c|c|c|c|c|c|}
\hline \multirow[t]{2}{*}{ Sl. No. } & \multirow[t]{2}{*}{ Reference } & \multirow[t]{2}{*}{$\begin{array}{l}\text { No. of test } \\
\text { data }\end{array}$} & \multirow[t]{2}{*}{$f_{c}(\mathbf{M P a})$} & \multirow[t]{2}{*}{ Type } & \multicolumn{2}{|c|}{$\begin{array}{c}\text { Minor Principal } \\
\text { Stress (MPa) }\end{array}$} & \multicolumn{2}{|c|}{$\begin{array}{c}\text { Intermediate } \\
\text { principal stress } \\
\text { (MPa) }\end{array}$} & \multicolumn{2}{|c|}{$\begin{array}{c}\text { Major Principal } \\
\text { stress (MPa) }\end{array}$} \\
\hline & & & & & Min & $\max$ & Min & $\max$ & Min & $\max$ \\
\hline 1 & Liu and Song (2010) & 11 & 20.00 & NSC & 0 & 47.00 & 0 & 176.17 & 20.00 & 188.01 \\
\hline 2 & Shang and Ji (2014) & 5 & 34.20 & NSC & 0 & 14.48 & 0 & 112.12 & 34.20 & 141.82 \\
\hline 3 & Zhou et al. (2014) - I & 16 & 44.13 & NSC & 0 & 14.96 & 0 & 132.42 & 44.13 & 149.45 \\
\hline 4 & Hampel et al. (2009) - I & 10 & 46.09 & NSC & 0 & 34.57 & 0 & 176.99 & 46.09 & 231.83 \\
\hline 5 & Wang et al. (1987) - I & 13 & 9.37 & NSC & 0 & 29.21 & 0 & 29.45 & 9.37 & 96.11 \\
\hline 6 & Wang et al. (1987) - II & 15 & 10.74 & NSC & 0 & 18.47 & 0 & 45.11 & 10.74 & 91.30 \\
\hline 7 & $\begin{array}{l}\text { Mills and Zimmerman } \\
\qquad(1970)-\mathrm{I}\end{array}$ & 37 & 23.03 & $\mathrm{NSC}$ & 2.90 & 8.69 & 2.90 & 72.41 & 41.03 & 82.07 \\
\hline 8 & $\begin{array}{l}\text { Mills and Zimmerman } \\
\qquad(1970)-\text { II }\end{array}$ & 16 & 26.93 & NSC & 0.62 & 7.24 & 1.45 & 62.76 & 41.52 & 71.24 \\
\hline 9 & $\begin{array}{l}\text { Mills and Zimmerman } \\
\qquad(1970)-\text { III }\end{array}$ & 16 & 36.10 & NSC & 0.62 & 4.83 & 1.45 & 67.59 & 48.28 & 73.10 \\
\hline 10 & M20 (Present Study) & 21 & 24.23 & NSC & 0 & 10 & 0 & 30 & 24.23 & 89.91 \\
\hline 11 & M30 (Present study) & 11 & 34.67 & NSC & 0 & 10 & 0 & 30 & 34.67 & 119.67 \\
\hline
\end{tabular}


Table 6 b: Available database of true-triaxial compression test conducted on plain concrete (High Strength Concrete, HSC)

\begin{tabular}{|c|c|c|c|c|c|c|c|c|c|c|}
\hline \multirow[t]{2}{*}{ Sl. No. } & \multirow[t]{2}{*}{ Reference } & \multirow[t]{2}{*}{$\begin{array}{c}\text { No. of } \\
\text { test } \\
\text { data }\end{array}$} & \multirow[t]{2}{*}{$f_{c}$ (MPa) } & \multirow[t]{2}{*}{ Type } & \multicolumn{2}{|c|}{$\begin{array}{c}\text { Minor Principal } \\
\text { Stress (MPa) }\end{array}$} & \multicolumn{2}{|c|}{$\begin{array}{c}\text { Intermediate } \\
\text { principal stress } \\
\text { (MPa) }\end{array}$} & \multicolumn{2}{|c|}{$\begin{array}{c}\text { Major Principal } \\
\text { stress (MPa) }\end{array}$} \\
\hline & & & & & Min & $\max$ & Min & $\max$ & Min & $\max$ \\
\hline 1 & He and Song (2010) & 7 & 60.16 & HSC & 0 & 15.77 & 0 & 131.64 & 60.16 & 157.74 \\
\hline 3 & Zhou et al. (2014) - III & 16 & 90.64 & HSC & 0 & 27.10 & 0 & 238.11 & 90.64 & 270.92 \\
\hline 4 & Hampel et al. (2009) - II & 10 & 72.73 & HSC & 0 & 40.00 & 0 & 226.92 & 72.73 & 268.37 \\
\hline 5 & Hampel et al. (2009) - III & 9 & 83.44 & HSC & 0 & 44.22 & 0 & 268.68 & 83.44 & 292.87 \\
\hline
\end{tabular}


Table 7 a: Calculation of criterion parameters for experimental data present in literature (Normal Strength concrete, NSC)

\begin{tabular}{|c|c|c|c|c|c|c|c|}
\hline \multirow{3}{*}{$\begin{array}{l}\text { Sl. } \\
\text { No. }\end{array}$} & \multirow{3}{*}{ Reference } & \multirow{3}{*}{$\begin{array}{c}f_{c} \\
(\mathbf{M P a})\end{array}$} & \multicolumn{5}{|c|}{ Material constant } \\
\hline & & & \multicolumn{3}{|c|}{ Bresler-Pester criterion } & \multicolumn{2}{|c|}{$\begin{array}{c}\text { Drucker Prager } \\
\text { criterion }\end{array}$} \\
\hline & & & $\alpha$ & $\mathbf{b}$ & c & $\alpha$ & $\mathbf{k} / \mathbf{f}_{\mathbf{c}}$ \\
\hline 1 & Liu and Song (2010) & 20.00 & 0.108 & -0.82 & -0.052 & -0.185 & 0.654 \\
\hline 2 & Shang and Ji (2014) & 34.20 & -0.092 & -1.864 & -0.525 & -0.203 & 0.469 \\
\hline 3 & Zhou et al. (2014) & 44.13 & 0.353 & -0.440 & 0.001 & -0.170 & 0.527 \\
\hline 4 & Hampel et al. (2009) -I & 46.09 & 0.231 & -0.745 & -0.084 & -0.186 & 0.525 \\
\hline 5 & Wang et al. (1987) - I & 9.37 & 0.251 & -0.842 & -0.049 & -0.218 & 0.773 \\
\hline 6 & Wang et al. (1987) - II & 10.74 & 0.326 & -0.545 & 0.002 & -0.226 & 0.385 \\
\hline 7 & $\begin{array}{c}\text { Mills and Zimmerman } \\
\text { (1970) - I }\end{array}$ & 23.03 & 0.387 & -0.635 & -0.098 & -0.146 & 0.688 \\
\hline 8 & $\begin{array}{l}\text { Mills and Zimmerman } \\
\qquad(1970)-\text { II }\end{array}$ & 26.93 & 0.169 & -1.177 & -0.420 & -0.144 & 0.642 \\
\hline 9 & $\begin{array}{l}\text { Mills and Zimmerman } \\
\qquad(1970)-\text { III }\end{array}$ & 36.10 & 0.408 & -0.564 & -0.199 & -0.095 & 0.651 \\
\hline 10 & M20 (Present Study) & 24.23 & 0.208 & -0.820 & -0.092 & -0.256 & 0.364 \\
\hline 11 & M30 (Present study) & 34.67 & 0.243 & -0.669 & 0.056 & -0.317 & 0.243 \\
\hline
\end{tabular}


Table 7 b: Calculation of criterion parameters for experimental data present in literature (High Strength concrete, HSC)

\begin{tabular}{|c|c|c|c|c|c|c|c|}
\hline \multirow{3}{*}{$\begin{array}{c}\text { Sl. } \\
\text { No. }\end{array}$} & \multirow[t]{3}{*}{ Reference } & \multirow{3}{*}{$\begin{array}{c}f_{c} \\
(\mathbf{M P a})\end{array}$} & \multicolumn{5}{|c|}{ Material constant } \\
\hline & & & \multicolumn{3}{|c|}{ Bresler-Pester criterion } & \multicolumn{2}{|c|}{$\begin{array}{c}\text { Drucker Prager } \\
\text { criterion }\end{array}$} \\
\hline & & & $\alpha$ & $\mathbf{b}$ & $\mathbf{c}$ & $\alpha$ & $\mathbf{k} / \mathbf{f}_{\mathbf{c}}$ \\
\hline 1 & He and Song (2010) & 60.16 & 0.100 & -1.295 & -0.483 & -0.145 & 0.562 \\
\hline 2 & Zhou et al. (2014) - II & 66.43 & 0.375 & -0.505 & -0.042 & -0.165 & 0.522 \\
\hline 3 & Zhou et al. (2014) - III & 90.64 & 0.378 & -0.498 & -0.053 & -0.155 & 0.535 \\
\hline 4 & Hampel et al. (2009) - II & 72.73 & 0.207 & -0.861 & -0.170 & -0.164 & 0.562 \\
\hline 5 & Hampel et al. (2009) - III & 83.44 & 0.250 & -0.733 & -0.120 & -0.167 & 0.529 \\
\hline
\end{tabular}


Table 8 a: Error in prediction of criterion parameters for experimental data present in literature (Normal Strength concrete, NSC)

\begin{tabular}{|c|c|c|c|c|c|c|c|}
\hline \multirow[t]{3}{*}{$\begin{array}{l}\text { SI. } \\
\text { No. }\end{array}$} & \multirow[t]{3}{*}{ Reference } & \multirow[t]{3}{*}{$\begin{array}{c}f_{c} \\
(\mathrm{MPa})\end{array}$} & \multicolumn{5}{|c|}{$\begin{array}{l}\text { Absolute error in calculation of material } \\
\text { constant }\end{array}$} \\
\hline & & & \multicolumn{3}{|c|}{ Bresler-Pester criterion } & \multicolumn{2}{|c|}{$\begin{array}{c}\text { Drucker Prager } \\
\text { criterion }\end{array}$} \\
\hline & & & $\alpha$ & $\mathbf{b}$ & c & $\alpha$ & $\mathbf{k} / \mathbf{f}_{\mathbf{c}}$ \\
\hline 1 & Liu and Song (2010) & 20.00 & 0.009 & 0.712 & 1.193 & 0.119 & 0.143 \\
\hline 2 & Shang and Ji (2014) & 34.20 & 0.191 & 0.332 & 0.721 & 0.137 & 0.042 \\
\hline 3 & Zhou et al. (2014) & 44.13 & 0.254 & 1.092 & 1.245 & 0.103 & 0.0162 \\
\hline 4 & Hampel et al. (2009) -I & 46.09 & 0.132 & 0.787 & 1.161 & 0.120 & 0.014 \\
\hline 5 & Wang et al. (1987) - I & 9.37 & 0.152 & 0.690 & 1.196 & 0.151 & 0.263 \\
\hline 6 & Wang et al. (1987) - II & 10.74 & 0.227 & 0.987 & 1.247 & 0.160 & 0.126 \\
\hline 7 & $\begin{array}{l}\text { Mills and Zimmerman } \\
\qquad(1970)-\mathrm{I}\end{array}$ & 23.03 & 0.288 & 0.897 & 1.147 & 0.080 & 0.178 \\
\hline 8 & $\begin{array}{l}\text { Mills and Zimmerman } \\
\qquad(1970)-\text { II }\end{array}$ & 26.93 & 0.07 & 0.355 & 0.825 & 0.077 & 0.131 \\
\hline 9 & $\begin{array}{l}\text { Mills and Zimmerman } \\
\qquad(1970)-\text { III }\end{array}$ & 36.10 & 0.309 & 0.968 & 1.046 & 0.028 & 0.141 \\
\hline 10 & M20 (Present Study) & 24.23 & 0.109 & 0.712 & 1.153 & 0.190 & 0.147 \\
\hline 11 & M30 (Present study) & 34.67 & 0.144 & 0.863 & 1.301 & 0.250 & 0.268 \\
\hline & Overall RMSE & & 0.193 & 0.798 & 1.126 & 0.141 & 0.157 \\
\hline
\end{tabular}


Table 8 b: Error in prediction of criterion parameters obtained from experimental data (High Strength concrete, HSC)

\begin{tabular}{|c|c|c|c|c|c|c|c|}
\hline \multirow[t]{3}{*}{$\begin{array}{l}\text { Sl. } \\
\text { No. }\end{array}$} & \multirow[t]{3}{*}{ Reference } & \multirow[t]{3}{*}{$\begin{array}{c}f_{c} \\
(\mathrm{MPa})\end{array}$} & \multicolumn{5}{|c|}{$\begin{array}{c}\text { Absolute error in calculation of criterion } \\
\text { parameters }\end{array}$} \\
\hline & & & \multicolumn{3}{|c|}{ Bresler-Pester criterion } & \multicolumn{2}{|c|}{$\begin{array}{c}\text { Drucker Prager } \\
\text { criterion }\end{array}$} \\
\hline & & & $\alpha$ & $\mathbf{b}$ & c & $\alpha$ & $\mathbf{k} / \mathbf{f}_{\mathbf{c}}$ \\
\hline 1 & He and Song (2010) & 60.16 & 0.001 & 0.237 & 0.762 & 0.078 & 0.052 \\
\hline 2 & Zhou et al. (2014) - II & 66.43 & 0.276 & 1.027 & 1.204 & 0.099 & 0.011 \\
\hline 3 & Zhou et al. (2014) - III & 90.64 & 0.279 & 1.034 & 1.192 & 0.088 & 0.024 \\
\hline 4 & Hampel et al. (2009) - II & 72.73 & 0.108 & 0.672 & 1.075 & 0.097 & 0.051 \\
\hline 5 & Hampel et al. (2009) - III & 83.44 & 0.151 & 0.800 & 1.125 & 0.101 & 0.0184 \\
\hline & Overall RMSE & & 0.194 & 0.809 & 1.084 & 0.093 & 0.036 \\
\hline
\end{tabular}


Table 9 a: Predictability indices for various criteria for Normal Strength Criterion (NSC)

\begin{tabular}{|c|c|c|c|c|c|c|c|c|c|}
\hline \multirow{3}{*}{ Reference } & \multicolumn{9}{|c|}{ Predictability indices } \\
\hline & \multicolumn{3}{|c|}{ Bresler-Pester criterion } & \multicolumn{3}{|c|}{ Drucker Prager criterion } & \multicolumn{3}{|c|}{ Hsieh-Ting-Chen criterion } \\
\hline & RMSE & $\psi^{2}$ & $R^{2}$ & RMSE & $\psi^{2}$ & $R^{2}$ & RMSE & $\psi^{2}$ & $R^{2}$ \\
\hline Liu and Song (2010) & 63.603 & 1.186 & 0.424 & 62.838 & 1.157 & 0.421 & 12.517 & 0.046 & 0.959 \\
\hline Shang and Ji (2014) & 51.439 & 1.729 & 0.244 & 47.331 & 1.464 & 0.342 & 20.570 & 0.277 & 0.906 \\
\hline Zhou et al. (2014) & 35.583 & 1.564 & 0.256 & 35.263 & 1.536 & 0.427 & 37.515 & 1.739 & 0.649 \\
\hline Hampel et al. (2009) -I & 63.231 & 1.379 & 0.388 & 58.034 & 1.162 & 0.518 & 39.805 & 0.547 & 0.805 \\
\hline Wang et al. (1987) - I & 41.318 & 3.017 & 0.547 & 31.610 & 1.766 & 0.933 & 6.756 & 0.081 & 0.970 \\
\hline Wang et al. (1987) - II & 36.620 & 2.083 & 0.223 & 36.026 & 1.958 & 0.237 & 5.431 & 0.046 & 0.958 \\
\hline Mills and Zimmerman (1970) - I & 26.006 & 3.912 & 0.174 & 24.06 & 3.349 & 0.321 & 17.282 & 1.726 & 0.699 \\
\hline Mills and Zimmerman (1970) - II & 19.069 & 2.668 & 0.075 & 20.01 & 2.937 & 0.074 & 18.046 & 2.389 & $\mathbf{0 . 3 7 7}$ \\
\hline Mills and Zimmerman (1970) - III & 12.691 & 1.715 & 0.358 & 14.90 & 2.365 & 0.247 & 13.211 & 1.859 & 0.667 \\
\hline M20 (Present Study) & 26.854 & 2.671 & 0.880 & 23.835 & 2.104 & 0.942 & 8.583 & 0.273 & 0.938 \\
\hline M30 (Present study) & 36.002 & 2.426 & 0.601 & 35.982 & 2.423 & 0.589 & 6.590 & 0.081 & 0.947 \\
\hline overall & 35.904 & 0.996 & 0.532 & 33.837 & 0.884 & 0.614 & $\underline{19.345}$ & $\underline{0.289}$ & $\underline{0.865}$ \\
\hline
\end{tabular}


Table 9 b: Predictability indices for various criteria for High Strength Criterion (HSC)

\begin{tabular}{|c|c|c|c|c|c|c|c|c|c|}
\hline \multirow{3}{*}{ Reference } & \multicolumn{9}{|c|}{ Predictability indices } \\
\hline & \multicolumn{3}{|c|}{ Bresler-Pester criterion } & \multicolumn{3}{|c|}{ Drucker Prager criterion } & \multicolumn{3}{|c|}{ Hsieh-Ting-Chen criterion } \\
\hline & RMSE & $\psi^{2}$ & $R^{2}$ & RMSE & $\psi^{2}$ & $R^{2}$ & RMSE & $\psi^{2}$ & $R^{2}$ \\
\hline He and Song (2010) & 47.922 & 2.306 & 0.239 & 41.305 & 1.713 & 0.476 & 66.341 & 4.418 & 0.772 \\
\hline Zhou et al. (2014) - II & 49.382 & 1.560 & 0.358 & 48.673 & 1.515 & 0.438 & 60.327 & 2.327 & 0.644 \\
\hline Zhou et al. (2014) - III & 60.556 & 1.631 & 0.339 & $\mathbf{5 9 . 5 8 6}$ & 1.580 & 0.434 & 89.260 & 3.544 & 0.595 \\
\hline Hampel et al. (2009) - II & 76.207 & 1.719 & 0.315 & 71.9 & 1.53 & 0.418 & 79.169 & 1.855 & 0.742 \\
\hline Hampel et al. (2009) - III & 77.0123 & 1.531 & 0.361 & 71.09 & 1.304 & 0.468 & 77.991 & 1.570 & 0.475 \\
\hline overall & 62.314 & 1.262 & 0.45 & $\underline{59.283}$ & $\underline{1.142}$ & $\underline{0.543}$ & 75.878 & 1.870 & 0.67 \\
\hline
\end{tabular}




\section{$\underline{\text { Appendix - A }}$}

\section{$\underline{\text { True-triaxial strength Database for plain cement concrete }}$}

Table A1. He and Song (2010)

\begin{tabular}{|llll|}
\hline$f_{c}$ & $\sigma_{3}$ & $\sigma_{2}$ & $\sigma_{1}$ \\
\hline 60.16 & 0 & 0 & 60.16 \\
60.16 & 12.03 & 12.03 & 120.28 \\
60.16 & 14.36 & 38.78 & 143.63 \\
60.16 & 15.34 & 64.43 & 153.4 \\
60.16 & 15.77 & 82.03 & 157.74 \\
60.16 & 15.25 & 117.45 & 152.53 \\
60.16 & 13.16 & 131.64 & 131.64 \\
\hline
\end{tabular}

Table A2. Liu and Song (2010)

\begin{tabular}{|llll|}
\hline$f_{c}$ & $\sigma_{3}$ & $\sigma_{2}$ & $\sigma_{1}$ \\
\hline 20 & 0.00 & 0.00 & 20.00 \\
20 & 5.24 & 5.24 & 52.43 \\
20 & 7.36 & 18.40 & 73.60 \\
20 & 7.18 & 21.53 & 71.77 \\
20 & 7.02 & 35.10 & 70.20 \\
20 & 6.21 & 46.60 & 62.13 \\
20 & 6.17 & 61.71 & 61.71 \\
20 & 37.34 & 37.34 & 149.35 \\
20 & 47.00 & 56.40 & 188.01 \\
20 & 46.82 & 93.64 & 187.28 \\
20 & 44.04 & 176.17 & 176.17 \\
\hline
\end{tabular}

Table A3. Shang and Ji (2014)

\begin{tabular}{|llll|}
\hline$f_{c}$ & $\sigma_{3}$ & $\sigma_{2}$ & $\sigma_{1}$ \\
\hline 34.2 & 0.00 & 0.00 & 34.20 \\
34.2 & 13.47 & 33.67 & 134.66 \\
34.2 & 14.18 & 70.91 & 141.82 \\
34.2 & 12.68 & 95.09 & 126.78 \\
34.2 & 11.21 & 112.12 & 112.12 \\
\hline
\end{tabular}

Table A4a. Hampel et al. (2009)

\begin{tabular}{|llll|}
\hline$f_{c}$ & $\sigma_{3}$ & $\sigma_{2}$ & $\sigma_{1}$ \\
\hline 46.09 & 0 & 0 & 46.09 \\
46.09 & 5.07 & 20.28 & 102.78 \\
46.09 & 5.07 & 63.60 & 106.47 \\
46.09 & 4.61 & 88.49 & 93.10 \\
46.09 & 14.29 & 29.04 & 144.72 \\
46.09 & 16.59 & 100.02 & 166.85 \\
46.09 & 13.37 & 129.51 & 136.43 \\
46.09 & 30.42 & 41.02 & 204.64 \\
46.09 & 34.57 & 139.19 & 231.83 \\
46.09 & 27.65 & 176.99 & 186.20 \\
\hline
\end{tabular}

Table A4b. Hampel et al. (2009)

\begin{tabular}{|llll|}
\hline$f_{c}$ & $\sigma_{3}$ & $\sigma_{2}$ & $\sigma_{1}$ \\
\hline 72.73 & 0 & 0 & 72.73 \\
72.73 & 7.27 & 28.36 & 144.01 \\
72.73 & 8.00 & 100.37 & 167.28 \\
72.73 & 7.27 & 141.82 & 149.10 \\
72.73 & 20.36 & 40.73 & 203.64 \\
72.73 & 22.55 & 134.55 & 224.74 \\
72.73 & 20.36 & 192.73 & 202.92 \\
72.73 & 40.00 & 53.09 & 266.19 \\
72.73 & 40.00 & 161.46 & 268.37 \\
72.73 & 35.64 & 226.92 & 238.55 \\
\hline
\end{tabular}

Table A4c. Hampel et al. (2009)

\begin{tabular}{|llll|}
\hline$f_{c}$ & $\sigma_{3}$ & $\sigma_{2}$ & $\sigma_{1}$ \\
\hline 83.44 & 0 & 0 & 83.44 \\
83.44 & 8.34 & 33.38 & 167.71 \\
83.44 & 8.34 & 102.63 & 171.89 \\
83.44 & 7.51 & 148.52 & 156.87 \\
83.44 & 22.53 & 45.89 & 228.63 \\
83.44 & 23.36 & 141.01 & 235.30 \\
83.44 & 20.86 & 201.09 & 211.94 \\
83.44 & 44.22 & 58.41 & 292.87 \\
83.44 & 42.55 & 268.68 & 282.86 \\
\hline
\end{tabular}


Table A5a. Zhou et al. (2014)

\begin{tabular}{|llll|}
\hline$f_{c}$ & $\sigma_{3}$ & $\sigma_{2}$ & $\sigma_{1}$ \\
\hline 44.13 & 0.00 & 0.00 & 44.13 \\
44.13 & 1.85 & 7.45 & 74.48 \\
44.13 & 1.94 & 19.61 & 78.45 \\
44.13 & 2.07 & 41.23 & 82.47 \\
44.13 & 2.03 & 60.63 & 80.84 \\
44.13 & 1.90 & 75.76 & 75.76 \\
44.13 & 4.24 & 8.43 & 84.32 \\
44.13 & 4.68 & 23.40 & 93.59 \\
44.13 & 5.03 & 50.30 & 100.61 \\
44.13 & 4.85 & 72.51 & 96.68 \\
44.13 & 4.63 & 92.22 & 92.22 \\
44.13 & 10.99 & 10.98 & 109.78 \\
44.13 & 14.12 & 35.27 & 141.07 \\
44.13 & 14.96 & 74.73 & 149.45 \\
44.13 & 14.30 & 107.22 & 142.97 \\
44.13 & 13.24 & 132.42 & 132.42 \\
44.13 & 0.00 & 0.00 & 44.13 \\
44.13 & 1.85 & 7.45 & 74.48 \\
44.13 & 1.94 & 19.61 & 78.45 \\
44.13 & 2.07 & 41.23 & 82.47 \\
\hline
\end{tabular}

Table A5b. Zhou et al. (2014)

\begin{tabular}{|llll|}
\hline$f_{c}$ & $\sigma_{3}$ & $\sigma_{2}$ & $\sigma_{1}$ \\
\hline 66.43 & 0.00 & 0.00 & 66.43 \\
66.43 & 2.66 & 10.72 & 107.16 \\
66.43 & 2.86 & 28.65 & 114.60 \\
66.43 & 2.99 & 59.99 & 119.98 \\
66.43 & 2.92 & 87.84 & 117.12 \\
66.43 & 2.72 & 108.95 & 108.95 \\
66.43 & 6.18 & 12.32 & 123.17 \\
66.43 & 6.78 & 34.03 & 136.12 \\
66.43 & 7.44 & 74.44 & 148.88 \\
66.43 & 7.24 & 108.62 & 144.82 \\
66.43 & 6.78 & 135.26 & 135.26 \\
66.43 & 15.41 & 15.39 & 153.93 \\
66.43 & 20.46 & 51.20 & 204.81 \\
66.43 & 20.99 & 104.86 & 209.73
\end{tabular}

\begin{tabular}{|llll|}
66.43 & 20.26 & 151.92 & 202.55 \\
66.43 & 19.00 & 190.26 & 190.26 \\
66.43 & 0.00 & 0.00 & 66.43 \\
66.43 & 2.66 & 10.72 & 107.16 \\
66.43 & 2.86 & 28.65 & 114.60 \\
66.43 & 2.99 & 59.99 & 119.98 \\
\hline
\end{tabular}

Table A5c. Zhou et al. (2014)

\begin{tabular}{|llll|}
\hline$f_{c}$ & $\sigma_{3}$ & $\sigma_{2}$ & $\sigma_{l}$ \\
\hline 90.64 & 0.00 & 0.00 & 90.64 \\
90.64 & 3.63 & 14.52 & 145.21 \\
90.64 & 3.90 & 38.59 & 154.36 \\
90.64 & 3.99 & 79.08 & 158.17 \\
90.64 & 3.81 & 113.80 & 151.73 \\
90.64 & 3.63 & 146.29 & 146.29 \\
90.64 & 8.16 & 16.37 & 163.70 \\
90.64 & 8.88 & 44.62 & 178.47 \\
90.64 & 9.70 & 96.94 & 193.88 \\
90.64 & 9.34 & 140.38 & 187.17 \\
90.64 & 8.70 & 174.48 & 174.48 \\
90.64 & 20.76 & 20.76 & 207.57 \\
90.64 & 25.47 & 63.61 & 254.43 \\
90.64 & 27.10 & 135.46 & 270.92 \\
90.64 & 25.56 & 191.77 & 255.70 \\
90.64 & 23.84 & 238.11 & 238.11 \\
90.64 & 0.00 & 0.00 & 90.64 \\
90.64 & 3.63 & 14.52 & 145.21 \\
90.64 & 3.90 & 38.59 & 154.36 \\
90.64 & 3.99 & 79.08 & 158.17 \\
\hline
\end{tabular}


Table A6a. Wang et al. (1987)

\begin{tabular}{|llll|}
\hline$f_{c}$ & $\sigma_{3}$ & $\sigma_{2}$ & $\sigma_{1}$ \\
\hline 9.37 & 0.00 & 0.00 & 9.37 \\
9.37 & 3.90 & 3.87 & 37.00 \\
9.37 & 2.98 & 3.87 & 29.79 \\
9.37 & 4.39 & 8.51 & 45.29 \\
9.37 & 5.70 & 14.26 & 46.61 \\
9.37 & 4.55 & 18.82 & 46.13 \\
9.37 & 4.23 & 17.14 & 43.25 \\
9.37 & 5.05 & 26.57 & 52.86 \\
9.37 & 15.69 & 15.22 & 74.97 \\
9.37 & 12.42 & 11.54 & 58.15 \\
9.37 & 14.79 & 14.10 & 67.28 \\
9.37 & 29.03 & 28.65 & 96.11 \\
9.37 & 29.45 & 29.21 & 96.11 \\
\hline
\end{tabular}

Table A6b. Wang et al. (1987)

\begin{tabular}{|llll|}
\hline$f_{c}$ & $\sigma_{3}$ & $\sigma_{2}$ & $\sigma_{l}$ \\
\hline 10.74 & 0.00 & 0.00 & 10.74 \\
10.74 & 5.05 & 9.46 & 45.17 \\
10.74 & 4.88 & 14.26 & 49.02 \\
10.74 & 4.72 & 23.85 & 47.57 \\
10.74 & 4.72 & 36.00 & 48.05 \\
10.74 & 4.23 & 32.64 & 43.25 \\
10.74 & 3.90 & 34.08 & 38.44 \\
10.74 & 3.74 & 37.12 & 38.44 \\
10.74 & 3.74 & 38.40 & 38.44 \\
10.74 & 18.47 & 27.37 & 91.30 \\
10.74 & 17.49 & 25.93 & 86.02 \\
10.74 & 17.98 & 34.88 & 86.50 \\
10.74 & 18.31 & 36.48 & 91.30 \\
10.74 & 17.82 & 43.03 & 84.58 \\
10.74 & 18.39 & 45.11 & 91.30 \\
\hline
\end{tabular}


Table A7a. Mills and Zimmerman

\begin{tabular}{|llll|}
\hline$f_{c}$ & $\sigma_{3}$ & $\sigma_{2}$ & $\sigma_{I}$ \\
\hline 23.03 & 0.00 & 0.00 & 23.03 \\
23.03 & 5.79 & 5.79 & 53.10 \\
23.03 & 5.79 & 5.79 & 50.69 \\
23.03 & 5.79 & 11.59 & 57.93 \\
23.03 & 5.79 & 11.59 & 57.93 \\
23.03 & 5.79 & 17.38 & 53.10 \\
23.03 & 5.79 & 17.38 & 62.76 \\
23.03 & 5.79 & 23.17 & 65.17 \\
23.03 & 5.79 & 28.97 & 67.59 \\
23.03 & 5.79 & 34.76 & 67.59 \\
23.03 & 5.79 & 40.55 & 60.34 \\
23.03 & 5.79 & 47.86 & 56.83 \\
23.03 & 2.90 & 50.69 & 50.69 \\
23.03 & 8.69 & 67.59 & 77.24 \\
23.03 & 8.69 & 8.69 & 62.76 \\
23.03 & 8.69 & 14.48 & 72.41 \\
23.03 & 8.69 & 20.28 & 79.66 \\
23.03 & 8.69 & 26.07 & 79.66 \\
23.03 & 8.69 & 31.86 & 77.24 \\
23.03 & 8.69 & 37.66 & 82.07 \\
23.03 & 8.69 & 43.45 & 82.07 \\
23.03 & 8.69 & 49.24 & 82.07 \\
23.03 & 8.69 & 55.72 & 81.52 \\
23.03 & 8.69 & 60.83 & 82.07 \\
23.03 & 8.69 & 72.41 & 72.41 \\
23.03 & 2.90 & 2.90 & 41.03 \\
23.03 & 2.90 & 8.69 & 53.10 \\
23.03 & 2.90 & 14.90 & 53.10 \\
23.03 & 2.90 & 24.14 & 57.93 \\
23.03 & 2.90 & 20.28 & 55.52 \\
23.03 & 2.90 & 31.86 & 57.93 \\
23.03 & 2.90 & 37.24 & 55.52 \\
23.03 & 2.90 & 43.45 & 55.52 \\
23.03 & 2.90 & 49.31 & 57.93 \\
23.03 & 2.90 & 53.10 & 53.10 \\
23.03 & 2.90 & 2.90 & 43.45 \\
23.03 & 8.69 & 8.69 & 63.79 \\
23.03 & 5.79 & 63.79 & 65.17 \\
\hline
\end{tabular}

Table A7b. Mills and Zimmerman

\begin{tabular}{|llll|}
\hline$f_{c}$ & $\sigma_{3}$ & $\sigma_{2}$ & $\sigma_{I}$ \\
\hline 26.93 & 0.00 & 0.00 & 26.93 \\
26.93 & 0.62 & 50.69 & 50.69 \\
26.93 & 0.62 & 45.86 & 45.86 \\
26.93 & 1.24 & 49.66 & 53.10 \\
26.93 & 1.24 & 50.69 & 50.69 \\
26.93 & 2.90 & 62.76 & 62.76 \\
26.93 & 2.90 & 62.76 & 62.76 \\
26.93 & 1.45 & 1.45 & 41.52 \\
26.93 & 2.90 & 2.90 & 41.76 \\
26.93 & 4.83 & 5.24 & 56.28 \\
26.93 & 4.83 & 5.24 & 61.59 \\
26.93 & 7.24 & 7.24 & 71.24 \\
26.93 & 7.24 & 7.24 & 71.17 \\
26.93 & 1.45 & 21.72 & 58.90 \\
26.93 & 2.90 & 36.21 & 66.14 \\
26.93 & 1.45 & 21.72 & 61.59 \\
26.93 & 2.90 & 28.97 & 68.83 \\
\hline
\end{tabular}

Table A7c. Mills and Zimmerman

\begin{tabular}{|llll|}
\hline$f_{c}$ & $\sigma_{3}$ & $\sigma_{2}$ & $\sigma_{l}$ \\
\hline 36.10 & 0.00 & 0.00 & 36.10 \\
36.10 & 0.62 & 47.10 & 48.28 \\
36.10 & 0.62 & 51.66 & 53.10 \\
36.10 & 1.24 & 60.34 & 61.31 \\
36.10 & 1.24 & 50.69 & 51.24 \\
36.10 & 2.90 & 67.59 & 68.83 \\
36.10 & 2.90 & 66.62 & 68.34 \\
36.10 & 1.45 & 1.45 & 54.55 \\
36.10 & 2.90 & 2.90 & 59.38 \\
36.10 & 1.45 & 21.72 & 63.24 \\
36.10 & 2.90 & 28.97 & 72.90 \\
36.10 & 4.83 & 5.24 & 64.00 \\
36.10 & 4.83 & 4.83 & 73.10 \\
36.10 & 1.45 & 26.55 & 66.41 \\
36.10 & 2.90 & 28.97 & 68.83 \\
36.10 & 2.90 & 2.90 & 54.34 \\
36.10 & 1.45 & 1.45 & 51.66 \\
\hline
\end{tabular}




\section{Appendix-B}

Calculation of criterion parameter value:

\section{Drucker Pragger Criteria}

$$
\begin{aligned}
& f\left(I_{1} . J_{2}\right)=0 \\
& \text { or, } \alpha I_{1}+\sqrt{J_{2}}-k=0
\end{aligned}
$$

where, $\alpha$ and $k$ are material constant or criterion parameters.

and,

$$
\begin{aligned}
& I_{1}=\sigma_{1}+\sigma_{2}+\sigma_{3} \\
& J_{2}=\frac{1}{6}\left[\left(\sigma_{1}-\sigma_{2}\right)^{2}+\left(\sigma_{2}-\sigma_{3}\right)^{2}+\left(\sigma_{3}-\sigma_{1}\right)^{2}\right]
\end{aligned}
$$

The criterion parameters can be calculated considering two failure states i.e.

a. Uniaxial compressive strength:

$$
\sigma_{3}=\sigma_{2}=0 ; \sigma_{1}=f_{\mathrm{c}}
$$

b. Equal biaxial strength:

$$
\sigma_{3}=0 ; \sigma_{1}=\sigma_{2}=f_{\mathrm{bc}}
$$

Considering first failure state:

$$
I_{1}=f_{\mathrm{c}}
$$

and, $\quad J_{2}=\frac{f_{c}^{2}}{3}$

putting the value of $I_{1}$ and $J_{2}$ in equation A.2.2, we get,

$$
f_{c}\left(\alpha+\frac{1}{\sqrt{3}}\right)-k=0
$$


Similarly, considering second failure state:

$$
I_{1}=2 f_{b \mathrm{c}}
$$

and, $\quad J_{2}=\frac{f_{b c}^{2}}{3}$

putting the value of $I_{1}$ and $J_{2}$ in equation A.2.2, we get,

$$
f_{b c}\left(2 \alpha+\frac{1}{\sqrt{3}}\right)-k=0
$$

Equation A.2.9 and A.2.12 can be solved by considering the standard correlation between equal biaxial strength and uniaxial compressive strength as:

$$
f_{b c}=1.15 \cdot f_{c}
$$

Using equation A.2.13 and A.2.12 we get,

$$
f_{c}\left(2.30 \alpha+\frac{1.15}{\sqrt{3}}\right)-k=0
$$

Solving equation A.2.9 and A.2.14, we get

$$
\begin{aligned}
& \alpha=-0.0666 \\
& k=0.5107 \bullet f_{c}
\end{aligned}
$$

\section{Bresler-Pester Criteria}

$$
\begin{aligned}
& f\left(\tau_{o c t}, \sigma_{o c t}, f_{c}\right)=0 \\
& \frac{\tau_{o c t}}{f_{c}}=a-b \bullet \frac{\sigma_{o c t}}{f_{c}}+c \bullet\left(\frac{\sigma_{o c t}}{f_{c}}\right)^{2}
\end{aligned}
$$

where, $a, b$ and $c$ are material constant.

and, $\sigma_{o c t}$ and $\tau_{o c t}$ are octahedral normal and shear stress defined as: 


$$
\sigma_{o c t}=\frac{I_{1}}{3}
$$

and, $\quad \tau_{\text {oct }}=\sqrt{\frac{2}{3} J_{2}}$

The criterion

parameters can be calculated considering three failure states i.e.

a. Uniaxial compressive strength:

$$
\sigma_{3}=\sigma_{2}=0 ; \sigma_{1}=f_{c}
$$

b. Uniaxial tensile strength:

$$
\sigma_{1}=\sigma_{2}=0 ; \sigma_{3}=-f_{t}
$$

c. Equal biaxial strength:

$$
\sigma_{3}=0 ; \sigma_{1}=\sigma_{2}=f_{b c}
$$

Considering first failure state:

$$
\frac{\sigma_{o c t}}{f_{c}}=\frac{1}{3}
$$

and, $\quad \frac{\tau_{o c t}}{f_{c}}=\frac{\sqrt{2}}{3}$

putting the values in equation A.2.16, we get,

$$
a-\frac{b}{3}+\frac{c}{9}=0.4714
$$

Similarly, considering second failure state:

$$
\frac{\sigma_{o c t}}{f_{c}}=\frac{-f_{t}}{3 f_{c}}
$$

and, $\quad \frac{\tau_{o c t}}{f_{c}}=\frac{\sqrt{2}}{3} \frac{f_{t}}{f_{c}}$

putting the values in equation A.2.16, we get, 


$$
a+\left(\frac{b}{3}-\frac{\sqrt{2}}{3}\right) \frac{f_{t}}{f_{c}}+\frac{c}{9}\left(\frac{f_{t}}{f_{c}}\right)^{2}=0
$$

Similarly, considering third failure state:

$$
\frac{\sigma_{o c t}}{f_{c}}=\frac{2}{3} \frac{f_{b c}}{f_{c}}
$$

and, $\quad \frac{\tau_{o c t}}{f_{c}}=\frac{\sqrt{2}}{3} \frac{f_{b c}}{f_{c}}$

putting the values in equation A.2.16, we get,

$$
a-\left(\frac{2 b}{3}+\frac{\sqrt{2}}{3}\right) \frac{f_{b c}}{f_{c}}+\frac{4 c}{9}\left(\frac{f_{b c}}{f_{c}}\right)^{2}=0
$$

Equation A.2.27 and A.2.30 can be further simplified by considering the standard correlation between equal biaxial strength, uniaxial tensile strength and uniaxial compressive strength as:

$$
f_{t}=0.10 \bullet f_{c}
$$

and, $f_{b c}=1.15 \cdot f_{c}$

Using equation A.2.31 and A.2.27 we get,

$$
a+0.033 b+\frac{0.01}{9} c=0.047
$$

Similarly using equation, A.2.32 and A.2.30, we get

$$
a-0.766 b+0.587 c=0.542
$$

Now on solving equation A.2.24, A.2.33 and A.2.34, we get

$$
\mathrm{a}=0.099
$$




$$
\begin{aligned}
& \mathrm{b}=-1.532 \\
& \mathrm{c}=-1.245
\end{aligned}
$$

\section{Hseih-Ting-Chen (HTC) Criterion}

$$
f\left(I_{1} . J_{2}, \sigma_{1}\right)=0
$$

or, $\quad a \frac{J_{2}}{f_{c}^{2}}+b \frac{\sqrt{J_{2}}}{f_{c}}+c \frac{\sigma_{1}}{f_{c}}+d \frac{I_{1}}{f_{c}}=1$

where, $a, b, c$ and $d$ are material constant.

The criterion parameters can be calculated considering three failure states i.e.

a. Uniaxial compressive strength:

$$
\sigma_{3}=\sigma_{2}=0 ; \sigma_{1}=f_{c}
$$

b. Uniaxial tensile strength:

$$
\sigma_{1}=\sigma_{2}=0 ; \sigma_{3}=-f_{t}
$$

c. Equal biaxial strength:

$$
\sigma_{3}=0 ; \sigma_{1}=\sigma_{2}=f_{b c}
$$

d. Confined triaxial compression strength:

$$
\sigma_{2}=\sigma_{3}=f_{p c} ; \sigma_{1}=f_{c c}
$$

Considering first failure state:

$$
I_{1}=f_{\mathrm{c}}
$$

and, $\quad J_{2}=\frac{f_{c}^{2}}{3}$

putting the value of $I_{1}, \sigma_{1}$ and $J_{2}$ in equation A.2.36, we get,

$$
0.333 a+0.577 b+c+d=1
$$

Similarly, considering second failure state:

$$
I_{1}=-f_{\mathrm{t}}
$$


and, $\quad J_{2}=\frac{f_{t}^{2}}{3}$

putting the value of $I_{1}, \sigma_{1}$ and $J_{2}$ in equation A.2.36, we get,

$$
\frac{a}{3}\left(\frac{f_{t}}{f_{c}}\right)^{2}+\frac{b}{\sqrt{3}}\left(\frac{f_{t}}{f_{c}}\right)+d\left(\frac{-f_{t}}{f_{c}}\right)=1
$$

Similarly, considering third failure state:

$$
I_{1}=2 f_{b \mathrm{c}}
$$

and, $\quad J_{2}=\frac{f_{b c}^{2}}{3}$

putting the value of $I_{1}, \sigma_{1}$ and $J_{2}$ in equation A.2.36, we get,

$$
\frac{a}{3}\left(\frac{f_{b c}}{f_{c}}\right)^{2}+\frac{b}{\sqrt{3}}\left(\frac{f_{b c}}{f_{c}}\right)+c\left(\frac{f_{b c}}{f_{c}}\right)+2 d\left(\frac{f_{b c}}{f_{c}}\right)=1
$$

Similarly, considering fourth failure state:

$$
\begin{array}{r}
I_{1}=2 f_{p \mathrm{c}}+f_{\mathrm{cc}} \\
\text { and, } J_{2}=\frac{\left(f_{c c}-f_{p c}\right)^{2}}{3}
\end{array}
$$

putting the value of $I_{1}, \sigma_{1}$ and $J_{2}$ in equation A.2.36, we get,

$$
\frac{a}{3}\left(\frac{f_{c c}-f_{p c}}{f_{c}}\right)^{2}+\frac{b}{\sqrt{3}}\left(\frac{f_{c c}-f_{p c}}{f_{c}}\right)+c\left(\frac{f_{c c}}{f_{c}}\right)+d\left(\frac{f_{c c}+2 f_{p c}}{f_{c}}\right)=1
$$

Equation A.2.46, A.2.50 and A.2.53 can be further simplified by considering the standard correlation as:

$$
\begin{aligned}
& f_{t}=0.10 \bullet f_{c} \\
& f_{b c}=1.15 \bullet f_{c}
\end{aligned}
$$


and, for $f_{p c}=0.8 \cdot f_{c}, \quad f_{c c}=4.2 \cdot f_{c}$

using above mentioned correlation, Equation A.2.46, A.2.50 and A.2.53 are transformed as:

$$
\begin{aligned}
& 0.00333 a+0.0577 b-0.1 d=1 \\
& 0.4408 a+0.6639 b+1.15 c+2.30 d=1 \\
& 3.853 a+1.963 b+4.2 c+5.8 d=1
\end{aligned}
$$

Now on solving equation A.2.43, A.2.57, A.2.58 and A.2.59, we get

$$
\begin{aligned}
& a=2.002 \\
& b=16.806 \\
& c=-9.128 \\
& d=-0.236
\end{aligned}
$$

